\title{
Variations in tropospheric submicron particle size distributions across the European continent 2008-2009
}

D. C. S. Beddows ${ }^{1}$, M. Dall'Osto ${ }^{2}$, R. M. Harrison ${ }^{1,3}$, M. Kulmala ${ }^{4}$, A. Asmi ${ }^{4}$, A. Wiedensohler ${ }^{5}$, P. Laj $^{6}$, A.M. Fjaeraa ${ }^{7}$, K. Sellegri ${ }^{8}$, W. Birmili ${ }^{5}$, N. Bukowiecki ${ }^{9}$, E. Weingartner ${ }^{9}$, U. Baltensperger ${ }^{9}$, V. Zdimal $^{10}$, N. Zikova ${ }^{10}$, J.-P. Putaud ${ }^{11}$, A. Marinoni ${ }^{12}$, P. Tunved ${ }^{13}$, H.-C. Hansson ${ }^{13}$, M. Fiebig $^{7}$, N. Kivekäs ${ }^{14,15}$, E. Swietlicki ${ }^{14}$, H. Lihavainen ${ }^{15}$, E. Asmi ${ }^{15}$, V. Ulevicius ${ }^{16}$, P. P. Aalto ${ }^{4}$, N. Mihalopoulos ${ }^{17}$, N. Kalivitis ${ }^{17}$, I. Kalapov ${ }^{18}$, G. Kiss ${ }^{19}$, G. de Leeuw ${ }^{4,15,20}$, B. Henzing ${ }^{20}$, C. O'Dowd ${ }^{21}$, S. G. Jennings ${ }^{21}$, H. Flentje ${ }^{22}$, F. Meinhardt ${ }^{23}$, L. Ries ${ }^{24}$, H. A. C. Denier van der Gon ${ }^{20}$, and A. J. H. Visschedijk ${ }^{20}$

${ }^{1}$ National Centre for Atmospheric Science, School of Geography, Earth and Environmental Sciences, University of Birmingham, B15 2TT, UK

${ }^{2}$ Institut de Ciències del Mar, CSIC, Pg Marítim de la Barceloneta 37-49, 08003 Barcelona, Spain

${ }^{3}$ Department of Environmental Sciences / Center of Excellence in Environmental Studies, King Abdulaziz University, P.O. Box 80203, Jeddah, 21589, Saudi Arabia

${ }^{4}$ Department of Physics, University of Helsinki, P.O. Box 64, Helsinki, Finland

${ }^{5}$ Leibniz Institute for Tropospheric Research, Permoserstraße 15, 04318 Leipzig, Germany

${ }^{6}$ Laboratoire de Glaciologie et Geophysique de 1' Environnement Universite Joseph Fourier, Grenoble 1/CNRS, 38400 St.

Martin d'Heres, France

${ }^{7}$ NILU - Norwegian Institute for Air Research Instituttveien 18, 2027 Kjeller, Norway

${ }^{8}$ Laboratoire de Météorologie Physique, UMR 6016, CNRS/University of Clermont-Ferrand, Clermont-Ferrand, France

${ }^{9}$ Laboratory of Atmospheric Chemistry, Paul Scherrer Institute, 5232 Villigen PSI, Switzerland

${ }^{10}$ Laboratory of Aerosol Chemistry and Physics, Institute of Chemical Process Fundamentals of the AS CR, v.v.i., Rozvojova 135, 16502 Prague 6, Czech Republic

${ }^{11}$ European Commission, Joint Research Centre, Institute for Environment and Sustainability, 21027 (VA), Italy

${ }^{12}$ CNR-ISAC, Institute of Atmospheric Sciences and Climate, 40129, Bologna, Italy

${ }^{13}$ Department of Applied Environmental Science (ITM), Stockholm University, 10691 Stockholm, Sweden

${ }^{14}$ Department of Physics, Lund University, SE-22100, Lund, Sweden

${ }^{15}$ Finnish Meteorological Institute, Erik Palmenin aukio 1, P.O. Box 503, 00101, Helsinki, Finland

${ }^{16}$ Center for Physical Sciences and Technology, Savanoriu 231, 02300 Vilnius, Lithuania

${ }^{17}$ Environmental Chemical Processes Laboratory, Department of Chemistry, University of Crete, Greece

${ }^{18}$ Institute of Nuclear Research and Nuclear Energy, Bulgarian Academy of Sciences, Blvd. Tzarigradsko chaussee, 72, 1784 Sofia, Bulgaria

${ }^{19}$ MTA-PE Air Chemistry Research Group, P.O. Box 158, 8201 Veszprém, Hungary

${ }^{20}$ Netherlands Organisation for Applied Scientific Research TNO, Princetonlaan 6, 3508 TA Utrecht, the Netherlands

${ }^{21}$ National University of Ireland Galway, University Road, Galway, Ireland

${ }^{22}$ German Meteorological Service, Hohenpeissenberg Observatory, Albin-Schwaiger Weg 10, 82383 Hohenpeißenberg, Germany

${ }^{23}$ German Federal Environment Agency (UBA), Messnetzzentrale, Paul-Ehrlich-str. 29, 63225, Langen, Germany

${ }^{24}$ German Federal Environment Agency (UBA), Platform Zugspitze of GAW Global Station Zugspitze/Hohenpeissenberg, Zugspitze 5, 28475 Zugspitze, Germany

Correspondence to: R. M. Harrison (r.m.harrison@bham.ac.uk)

Received: 31 October 2013 - Published in Atmos. Chem. Phys. Discuss.: 29 November 2013

Revised: 19 February 2014 - Accepted: 11 March 2014 - Published: 30 April 2014 
Abstract. Cluster analysis of particle number size distributions from background sites across Europe is presented. This generated a total of nine clusters of particle size distributions which could be further combined into two main groups, namely: a south-to-north category (four clusters) and a westto-east category (five clusters). The first group was identified as most frequently being detected inside and around northern Germany and neighbouring countries, showing clear evidence of local afternoon nucleation and growth events that could be linked to movement of air masses from south to north arriving ultimately at the Arctic contributing to Arctic haze. The second group of particle size spectra proved to have narrower size distributions and collectively showed a dependence of modal diameter upon the longitude of the site (west to east) at which they were most frequently detected. These clusters indicated regional nucleation (at the coastal sites) growing to larger modes further inland. The apparent growth rate of the modal diameter was around 0.6$0.9 \mathrm{~nm} \mathrm{~h}^{-1}$.

Four specific air mass back-trajectories were successively taken as case studies to examine in real time the evolution of aerosol size distributions across Europe. While aerosol growth processes can be observed as aerosol traverses Europe, the processes are often obscured by the addition of aerosol by emissions en route. This study revealed that some of the 24 stations exhibit more complex behaviour than others, especially when impacted by local sources or a variety of different air masses. Overall, the aerosol size distribution clustering analysis greatly simplifies the complex data set and allows a description of aerosol aging processes, which reflects the longer-term average development of particle number size distributions as air masses advect across Europe.

\section{Introduction}

Airborne particle size distributions vary in space and time and can be interpreted in terms of known sources, meteorological processes and aerosol dynamical processes affecting such particles. Sources contributing to particle concentrations in the atmosphere are both primary and secondary. Traffic is often found to be the most important primary source for ultrafine particles in urban areas (Charron and Harrison, 2003; Harrison and Jones, 2005). Particles in rural areas are from a wider range of sources, both primary and secondary. New secondary particles formed by nucleation are generated from gas-to-particle conversion. Such particles have been observed at many surface locations around the world and also within the free and upper troposphere (Kulmala et al., 2004; Venzac et al., 2008; Boulon et al., 2010, 2011). Reddington et al. (2011) recently stressed the importance of understanding the relative contribution of primary and secondary particles in regional and global aerosol so that models can attribute aerosol radiative forcing to different sources.

Compliance monitoring of particle mass metrics is widely performed (EEA, 2009), but at present, measurement of particle number concentrations is not required. Nevertheless, as the importance of particle number concentration as a complement to the existing $\mathrm{PM}_{2.5}$ and $\mathrm{PM}_{10}$ metrics has become recognised, particle size distributions are increasingly being measured in the context of air quality at multiple locations. For example - at national level - the UK Particle Monitoring Programme operates three SMPS instruments at Harwell (the UK EUSAAR site), and at the London sites of North Kensington and Marylebone Road, all measuring submicrometre particle number size distributions, upon which numerous studies have been based (Charron et al., 2007; Beddows et al., 2009; Harrison et al., 2011). In Germany a similar initiative, established in 2008 by the German Environment Agency and known as the German Ultrafine Aerosol Network (GUAN), brings together several German institutes with an interest in sub-micrometre aerosol properties (Birmili et al., 2009). At the European level, the EUSAAR (European Supersites for Atmospheric Aerosol Research) project of the Sixth Framework Programme of the European Commission contributed to the development of a harmonised and quality-controlled network of measurements (Philippin et al., 2009; Asmi et al., 2011). The EUSAAR project coordinated 24 European sites measuring aerosol chemical, physical and optical properties following a standardised protocol of instrument maintenance, measurement procedures and data delivery using a common format to a single database (Wiedensohler et al., 2012). Recently, the EUSAAR project activities continued within the ACTRIS project (Philippin et al., 2009).

Asmi et al. (2011) presented a detailed overview of the sites and seasonally disaggregated size distributions collected at the EUSAAR and GUAN stations for the dry diameters between 30 and $500 \mathrm{~nm}$ for the years 2008 and 2009. The sites used to collect data are given in Table 1 and the reader is referred to Asmi et al. (2011) for a full account and description. It is important to note that all these sites are considered as remote or rural regional monitoring sites. Data were collected using either Differential Mobility Particle Sizer (DMPS) or Scanning Mobility Particle Sizer (SMPS) instruments and then harmonised into a single data set.

Briefly, Asmi et al. (2011) showed that the aerosol concentrations in Europe are highly variable spatially and divide their description into nine areas: central European; Mountain; Arctic; Balkans; Nordic, Baltic, north Italian; Mediterranean; western European (Fig. 1). Central European aerosol is observed at the low-altitude stations CBW, BOS, WAL, MPZ, OBK and KPO from the Netherlands along a belt of land passing across Germany, the Czech Republic, Slovakia and Hungary. These sites measure high concentrations of particles with almost unimodal median distributions but have small seasonal changes. South of this belt are the mountain stations of SSL, HPB, ZSF, JFJ and CMN. The mountain 
Table 1. Locations and names of stations used in the data analysis. The site altitudes are given with reference to standard sea level. The areas are grouped by European sub-divisions using definitions from the Central Intelligence Agency (2013). Country codes are given in the ISO 3166 standard.

\begin{tabular}{|c|c|c|c|c|c|}
\hline Station name & Station code & Country & $\begin{array}{l}\text { Coordinates, altitude } \\
\text { (lat., long., height.) }\end{array}$ & Site type & Instrument \\
\hline & & & $\begin{array}{l}\text { Low altitude sites } \\
\text { (less than } 1000 \mathrm{~m} \text { a.s.l.) }\end{array}$ & & \\
\hline \multicolumn{6}{|l|}{ Nordic and Baltic } \\
\hline Aspvreten & ASP & SE & $58^{\circ} 48^{\prime} \mathrm{N}, 17^{\circ} 23^{\prime} \mathrm{E}, 30 \mathrm{~m}$ & & DMPS \\
\hline Birkenes & BIR & NO & $58^{\circ} 23^{\prime} \mathrm{N}, 8^{\circ} 15^{\prime} \mathrm{E}, 190 \mathrm{~m}$ & Mostly remote & DMPS \\
\hline Pallas & PAL & FI & $67^{\circ} 58^{\prime} \mathrm{N}, 24^{\circ} 7^{\prime} \mathrm{E}, 560 \mathrm{~m}$ & Remote & DMPS \\
\hline Preila & PLA & $\mathrm{LT}$ & $55^{\circ} 55^{\prime} \mathrm{N}, 21^{\circ} 0^{\prime} \mathrm{E}, 5 \mathrm{~m}$ & Weakly influenced, general remote & SMPS \\
\hline SMEAR II & SMR & FI & $61^{\circ} 51^{\prime} \mathrm{N}, 24^{\circ} 17^{\prime} \mathrm{E}, 181 \mathrm{~m}$ & Mostly remote & DMPS \\
\hline Vavihil & VHL & SE & $56^{\circ} 1^{\prime} \mathrm{N}, 13^{\circ} 9^{\prime} \mathrm{E}, 172 \mathrm{~m}$ & Rural & DMPS \\
\hline \multicolumn{6}{|l|}{ Central Europe } \\
\hline Bösel & BOS & $\mathrm{DE}$ & $53^{\circ} \mathrm{N}, 7^{\circ} 57^{\prime} \mathrm{E}, 16 \mathrm{~m}$ & Rural & SMPS \\
\hline $\mathrm{K}$-Puszta & KPO & $\mathrm{HU}$ & $46^{\circ} 58^{\prime} \mathrm{N}, 19^{\circ} 19^{\prime} \mathrm{E}, 125 \mathrm{~m}$ & Rural & DMPS \\
\hline Melpitz & MPZ & $\mathrm{DE}$ & $51^{\circ} 32^{\prime} \mathrm{N}, 12^{\circ} 12^{\prime} \mathrm{E}, 87 \mathrm{~m}$ & Rural & DMPS \\
\hline Kosetice & OBK & $\mathrm{CZ}$ & $49^{\circ} 35^{\prime} \mathrm{N}, 15^{\circ} 15^{\prime} \mathrm{E}, 534 \mathrm{~m}$ & Rural & SMPS \\
\hline Hohenpeissenberg & HPB & $\mathrm{DE}$ & $47^{\circ} 48^{\prime} \mathrm{N}, 11^{\circ} 11^{\prime} \mathrm{E}, 988 \mathrm{~m}$ & Rural & SMPS \\
\hline Waldhof & WAL & $\mathrm{DE}$ & $52^{\circ} 31^{\prime} \mathrm{N}, 10^{\circ} 46^{\prime} \mathrm{E}, 70 \mathrm{~m}$ & Rural & SMPS \\
\hline \multicolumn{6}{|l|}{ Western Europe } \\
\hline Cabauw & CBW & NL & $51^{\circ} 18^{\prime} \mathrm{N}, 4^{\circ} 55^{\prime} \mathrm{E}, 60 \mathrm{~m}$ & Agglomeration & SMPS \\
\hline Harwell & HWL & UK & $51^{\circ} 34^{\prime} \mathrm{N}, 1^{\circ} 19^{\prime} \mathrm{W}, 60 \mathrm{~m}$ & Agglomeration & SMPS \\
\hline Mace Head & MHD & $\mathrm{IE}$ & $53^{\circ} 19^{\prime} \mathrm{N}, 9^{\circ} 53^{\prime} \mathrm{W}, 5 \mathrm{~m}$ & Generally remote & SMPS \\
\hline \multicolumn{6}{|l|}{ Mediterranean } \\
\hline Finokalia & FKL & GR & $35^{\circ} 20^{\prime} \mathrm{N}, 25^{\circ} 40^{\prime} \mathrm{E}, 250 \mathrm{~m}$ & Mostly remote & SMPS \\
\hline JRC-Ispra & IPR & IT & $45^{\circ} 49^{\prime} \mathrm{N}, 8^{\circ} 38^{\prime} \mathrm{E}, 209 \mathrm{~m}$ & Agglomeration & DMPS \\
\hline \multicolumn{6}{|l|}{ Arctic } \\
\hline \multirow[t]{2}{*}{ Zeppelin } & ZEP & NO & $78^{\circ} 55^{\prime} \mathrm{N}, 11^{\circ} 54^{\prime} \mathrm{E}, 474 \mathrm{~m}$ & Remote & DMPS \\
\hline & & & $\begin{array}{l}\text { High-altitude sites } \\
\text { (over } 1000 \mathrm{~m} \text { a.s.l.) }\end{array}$ & & \\
\hline \multicolumn{6}{|l|}{ Western Europe } \\
\hline Puy de Dôme & PDD & FR & $45^{\circ} 46^{\prime} \mathrm{N}, 2^{\circ} 57^{\prime} \mathrm{E}, 1465 \mathrm{~m}$ & Weakly influenced & SMPS \\
\hline \multicolumn{6}{|l|}{ Central Europe } \\
\hline Schauinsland & SSL & $\mathrm{DE}$ & $47^{\circ} 55^{\prime} \mathrm{N}, 7^{\circ} 55^{\prime} \mathrm{E}, 1210 \mathrm{~m}$ & Rural & SMPS \\
\hline Zugspitze & ZSF & $\mathrm{DE}$ & $47^{\circ} 25^{\prime} \mathrm{N}, 10^{\circ} 59^{\prime} \mathrm{E}, 2670 \mathrm{~m}$ & Weakly influenced & SMPS \\
\hline Jungfraujoch & JFJ & $\mathrm{CH}$ & $46^{\circ} 32^{\prime} \mathrm{N}, 7^{\circ} 59^{\prime} \mathrm{E}, 3580 \mathrm{~m}$ & Mostly remote & SMPS \\
\hline \multicolumn{6}{|l|}{ Balkans } \\
\hline BEO Moussala & BEO & BG & $42^{\circ} 10^{\prime} \mathrm{N}, 23^{\circ} 35^{\prime} \mathrm{E}, 2971 \mathrm{~m}$ & Mostly remote & SMPS \\
\hline \multicolumn{6}{|l|}{ Mediterranean } \\
\hline Monte Cimone & $\mathrm{CMN}$ & IT & $44^{\circ} 11^{\prime} \mathrm{N}, 10^{\circ} 41^{\prime} \mathrm{E}, 2165 \mathrm{~m}$ & Weakly influenced & DMPS \\
\hline
\end{tabular}

stations of SSL and HPB had many similarities with the lowaltitude boundary layer measurements and the higher mountains, at lower latitudes (including BEO) whose distributions characterised the Mountain aerosol. These had episodes of extremely clean air, most probably from the free troposphere, alternating with episodes of relatively polluted air masses, especially during daytime in summer. The stations with this kind of aerosol were JFJ, BEO, ZSF and CMN. In contrast, the North Italian aerosol from site IPR had very high number concentrations, especially during winter in the accumulation 


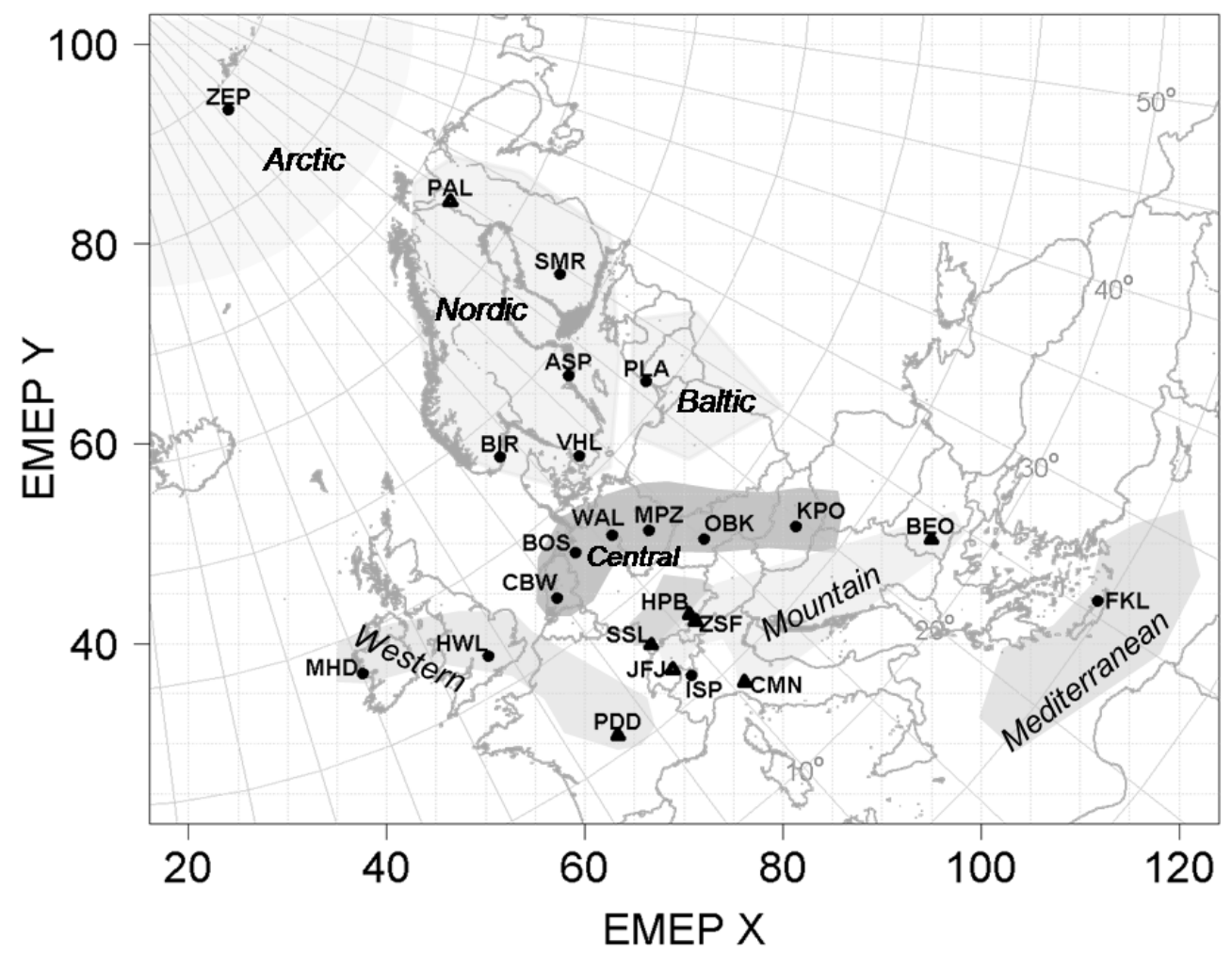

Fig. 1. Location of the 24 EUSAAR and GUAN stations in Table 1.

mode. Also at the lowest latitude site (FKL), a Mediterranean aerosol was measured with maximum number concentrations during summer and spring. At latitudes higher than the central European belt, the northern European aerosol had lower concentrations and the seasonal cycle has a strong effect on the particles in this region, and the overall variation is relatively large. The summer concentrations were usually greatest, especially for smaller particle sizes. The concentration distributions often show multiple modes, suggesting a combination of more polluted air masses, and cleaner air from the Arctic or Atlantic oceans. The stations included in this group were BIR, VHL, ASP and SMR. PAL has many similarities with other Nordic stations and had even more extreme seasonal variation and thus had some parameters in common with Arctic aerosol concentrations and variability. The Baltic PLA station was only partially similar to the Nordic stations, with both concentration histograms and size distributions showing influence from multiple source areas of particles and some similarities in concentration levels with the central European aerosol. The Arctic aerosol, with high seasonality, was observed at ZEP with very low number concentrations and evidence of Arctic haze events during dark winter periods. Then finally, the western European aerosol (MHD, PDD and HWL) showed clear influence of multiple sources of aerosol (clean and polluted), and with a strong seasonal cycle for smaller particle sizes.
The study of Asmi et al. (2011) is a landmark study in unifying particle size distribution data and average particle number concentrations. In this current work, we further extend the analysis by applying $k$-means cluster analysis to the particle size distributions (Beddows et al., 2009). A great advantage of this clustering method over the provision of average of aerosol size distributions (Asmi et al., 2011) is that it can provide a small number of size distributions, which can be compared across different time periods. Accordingly, the final cluster centres reflect particle number size distributions representative of each cluster. In other words, the clustering reduces the complexity of the data set and this simplification allows easier separation of different size distributions from a single site, intercomparison of these distributions across sites, and interpretation of aerosol dynamical processes as aerosol is advected across Europe.

\section{Methodology}

Although the instruments within the 24-site network of SMPS/DMPS devices used several different size ranges, all the data collected were harmonised into one large matrix by interpolating the data onto a common size bin scale; 121 size bins spanning 1 to $1000 \mathrm{~nm}$ with 40 channels per decade were used. Not all instruments shared the same size range or used the same size bins, hence blank lower and upper 
columns were trimmed from this matrix until every element had a value. In all, the reduced matrix had 54 size bins (17.8$375.8 \mathrm{~nm}$ ) and 117000 hourly particle size spectra (given the capture rates of the instruments across the EUSAAR network in 2008/2009).

The data are extracted from the EBAS database (http: //ebas.nilu.no), located at NILU (the Norwegian Institute for Air Research), which is a database hosting data for projects and programmes such as the European Monitoring and Evaluation Programme (EMEP), the Global Atmospheric Watch - World Data Centre for Aerosols (GAW-WDCA) and the European Aerosol, Clouds and Trace Gases Research Infrastructure (ACTRIS) network. The EBAS data were collected under UTC (Temps Universel Coordonné) and had a time resolution of $1 \mathrm{~h}$ and it was initially deemed preferable to cluster at this resolution. However, the method proposed by Beddows et al. (2009) to determine the optimum number of $k$-means clusters in Cran $\mathrm{R}$ (R Development Core Team, 2010), has a limited capacity to hold particle size spectra $(\sim 5000$ spectra per analysis running on a $32 \mathrm{bit} \mathrm{PC})$. Consequently, the data were analysed at hourly resolution using a giant data set clustering strategy (see Sect. 2.1) and then further reduced in number by averaging the spectra over different time periods (daily, weekly).

In order to group the data into a manageable number of groups, the data set (consisting of either hourly, daily or weekly averaged spectra) was analysed using $k$-means cluster analysis (Beddows et al., 2009). Given that $S_{k}$ represents the set of spectra in the $k$ th cluster and $\overline{\operatorname{spectrum}_{k, m}}$ represents the mean for the particle size bin mobility diameter $m$ over cluster $k$, the $k$-means method partitions the data into $G$ groups such that the "within-cluster sum of squares" expression is minimised using an iterative cycle:

$\sum_{k=1}^{G} \sum_{d \in S_{k}}\left\|\operatorname{spectrum}_{d, m}-\overline{\operatorname{spectrum}_{k, m}}\right\|^{2}$.

Known as the Hartigan and Wong (1979) method, this starts with a random initial partition and continually reassigns the particle size spectra to the clusters based on the similarity between the spectra and the cluster centres until a convergence criterion is met. The particle size distributions were normalised to their unit length in order to cluster shapes rather than clustering shapes of different magnitudes which would significantly increase the number of clusters.

\subsection{Hourly data}

For the analysis on an hourly resolution, we successfully tested the $k$-means functions provided in the CRAN RPackage BIRCH (Balanced Iterative Reducing and Clustering using Hierarchies). This package is used when dealing with very large data sets and it does not require that the data can fit in physical memory. BIRCH is an implementation of the algorithms described in Zhang et al. (1997), and provides functions for creating clustering feature trees, along with algorithms for applying $k$-means clustering (although limited to 30 size bins). This resulted in a nine-cluster result optimised using an RSS value (i.e. the total residual sum of squares of the clustering). However, the diurnal shifts in modal diameter are lost when clustering hourly spectra (see Figs. S1 and S2 in the Supplement). Even though cluster maxima and minima are evident over an average daily cycle when using hourly spectra, there is a tendency for each cluster result to be constrained to its mean spectrum type and thus dividing diurnal trends in the modal diameter over more than one cluster.

\subsection{Daily data}

In contrast to hourly data, a better solution was found with the daily averaged data. To determine the optimum number of clusters, a random selection of 5000 daily spectra was used indicating an optimum of nine clusters which gave a maximum in the Dunn indices $\left(6.45 \times 10^{-4}\right)$ and a silhouette width of 0.363 (Beddows et al., 2009). Subsequently the prenormalised particle size spectra were partitioned into nine groups using the cluster analysis assignments $(1,2, \ldots, 9)$ yielded from the clustering of the normalised data using a setting of $G=9$. Furthermore, even though daily average spectra were clustered, the average spectra making up these days could be disaggregated to form average hourly spectra for each cluster so that the diurnal variation of each could be understood and used to help characterise each cluster. This was considered to be one of the main strengths of this new approach.

\subsection{Weekly data}

This same strategy can then be applied to weekly averaged spectra to reveal weekday/weekend trends as well as seasonal trends (see results in Figures S3 and S4).

In summary, when clustering daily and weekly averaged spectra, particle growth behaviour is preserved and is visible over the plotted average - which can then be used to provide an improved characterisation of the cluster.

\section{Results}

\subsection{Overview of the particle size distribution clustering}

By clustering all of the spectra collected across the 24 EUSAAR sites, an understanding of how the spectrum types are shared between these sites can be observed. The daily spectra collected at each of the 24 EUSAAR sites over the years 2008 and 2009 can be summarised in nine $k$-means clusters (see Fig. 2). Six show strong ultrafine modes (Clusters 1, 2, $5,6,7$ and 8 have modal diameter $<100 \mathrm{~nm}$ ) and three show accumulation modes (Clusters 3, 4 and 9 have modal diameter $>100 \mathrm{~nm})$. 


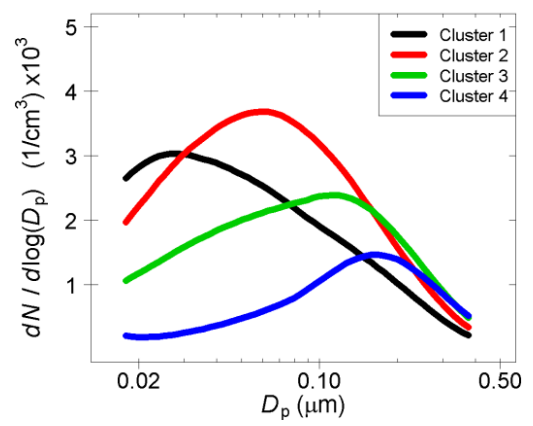

(a)

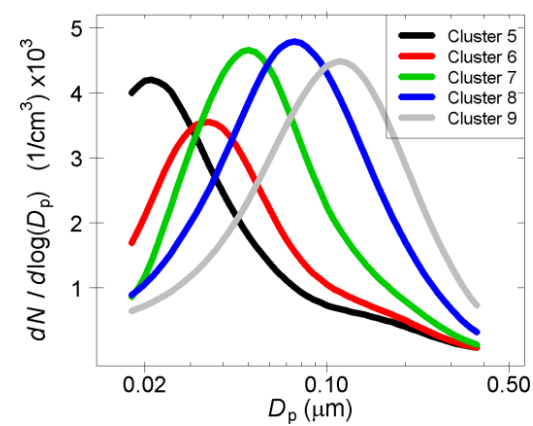

(b)

Fig. 2. Average cluster spectra resulting from the cluster analysis of the daily mean spectra collected at each of the 24 EUSAAR sites. (a) Clusters 1, 2 and 3 are the broad central European spectra and the Arctic spectrum 4 and (b) Clusters 5, 6, 7, 8 and 9 are the narrower size distributions observed at sites outside of the central European area.

Considering the size distributions, spatial patterns and temporal behaviour of the individual clusters in relation to the above sources and aging processes, examination of the particle size spectra in Fig. 2 suggests the following:

- Clusters 5 and 1 are associated mainly with nucleation processes. Cluster 1 appears more aged, as it contains a greater component of particles at larger diameters than Cluster 5.

- Clusters 9, 3 and 4 (modal diameters $>0.1 \mu \mathrm{m}$ ) represent well-aged accumulation mode particles.

- Cluster 6 (modal diameter 30-40 nm) is similar to the spectrum of freshly emitted road traffic exhaust, but given the rural or remote locations of the sampling sites, probably has other origins or comprises aged nucleation particles.

- Clusters 7, 8 and 2 lie in the range between the nucleation/combustion emission spectra and the accumulation mode spectra and probably represent intermediate aging or multiple mixed sources.

In Figs. 3 and S5 in the Supplement the cluster frequencies are plotted for each site. In Fig. 3, the sites have been grouped according to geographic factors (location, altitude, etc.) and show considerable similarities in pattern between sites within the same group. Features apparent are:

- Cluster 5, with the smallest modal diameter and more clearly indicative of nucleation appears most frequently at the cleaner sites: MHD, PAL, CMN, PDD, SMR and ZSF, including several of the high altitude sites.

- Cluster 1 shows a wider abundance, including relatively high frequencies at BOS, HPB, MHD, MPZ, PDD, SSL and ZSF, possibly reflecting nucleation in slightly more polluted air masses.
- Cluster 6 appears frequently at BIR, CMN, HWL, JFJ, PAL, PDD, SMR and may represent either fresh combustion emissions, or given the remote locations of most of the sites, probably represents aged nucleation particles.

- Clusters 7,8 and 2 which have modes between the nucleation group (i.e. $>35 \mathrm{~nm}$ ) and the accumulation mode group Cluster $9(<0.11 \mu \mathrm{m})$ appear more frequently at BIR, BOS, CBW, CMN, HPB, HWL, IPR, JFJ, KPO, MPZ, PAL, PDD, SMR, SSL, VHL, WAL, ZSF (i.e. almost all sites), with a clear distinction between those with a high frequency of Cluster 2 and those with mainly Cluster 7 and 8 . The reasons for this are unclear.

- Clusters 9, 3 and 4 representing clear accumulation mode particles appear frequently at BEO, CMN, FKL (Cluster 9 only), HPB (Cluster 3 only), IPR (Cluster 9 only), KPO, MHD (Cluster 3 only), MPZ (Cluster 3 only), OBK, PLA (Cluster 9 only), SMR, SSL (Cluster 3 only), VHL, ZSF and most notably at ZEP where the frequency of Cluster 4 far exceeds that of all others.

The overall conclusion of these results appears to be that nucleation affects all sites, but is common at only a few sites, and all sites experience aged aerosol to differing degrees. This is unsurprising in the context of atmospheric transport and the geography of Europe.

Figure 4 shows these modes in more detail and how the spectra vary across the quartile plots. For each cluster, the colour plots also show the dependence of the particle size spectra on the hour of the day and in this case, the benefits of clustering the daily average. Also shown are the monitoring sites at which the clusters are most frequently observed (see the European maps in Fig. 4 and also Fig. S5 in the Supplement which shows the frequency of occurrence at each site with latitude and longitude). In general when referring to Fig. 4, the broader multimodal distributions (Clusters 13) are most frequently detected in central Europe, where 


\begin{tabular}{|c|c|c|c|c|c|}
\hline \multirow[t]{2}{*}{$\begin{array}{l}\text { Outpost } \\
\text { sites. }\end{array}$} & $\begin{array}{l}\text { Nordic + } \\
\text { Westerly } \\
\text { sites }\end{array}$ & $\begin{array}{l}\text { Central } \\
\text { Europe } \\
\text { sites }\end{array}$ & $\begin{array}{l}\text { Mountain } \\
\text { sites }\end{array}$ & $\begin{array}{l}\text { Low Latitiude } \\
+ \text { Mountain } \\
\text { sites }\end{array}$ & $\begin{array}{l}\text { High } \\
\text { longitude } \\
\text { sites }\end{array}$ \\
\hline & $\begin{array}{l}\text { North to } \\
\text { South }\end{array}$ & $\begin{array}{l}\text { West to } \\
\text { East }\end{array}$ & & $\begin{array}{l}\text { West to } \\
\text { East }\end{array}$ & $\begin{array}{l}\text { North to } \\
\text { South }\end{array}$ \\
\hline
\end{tabular}
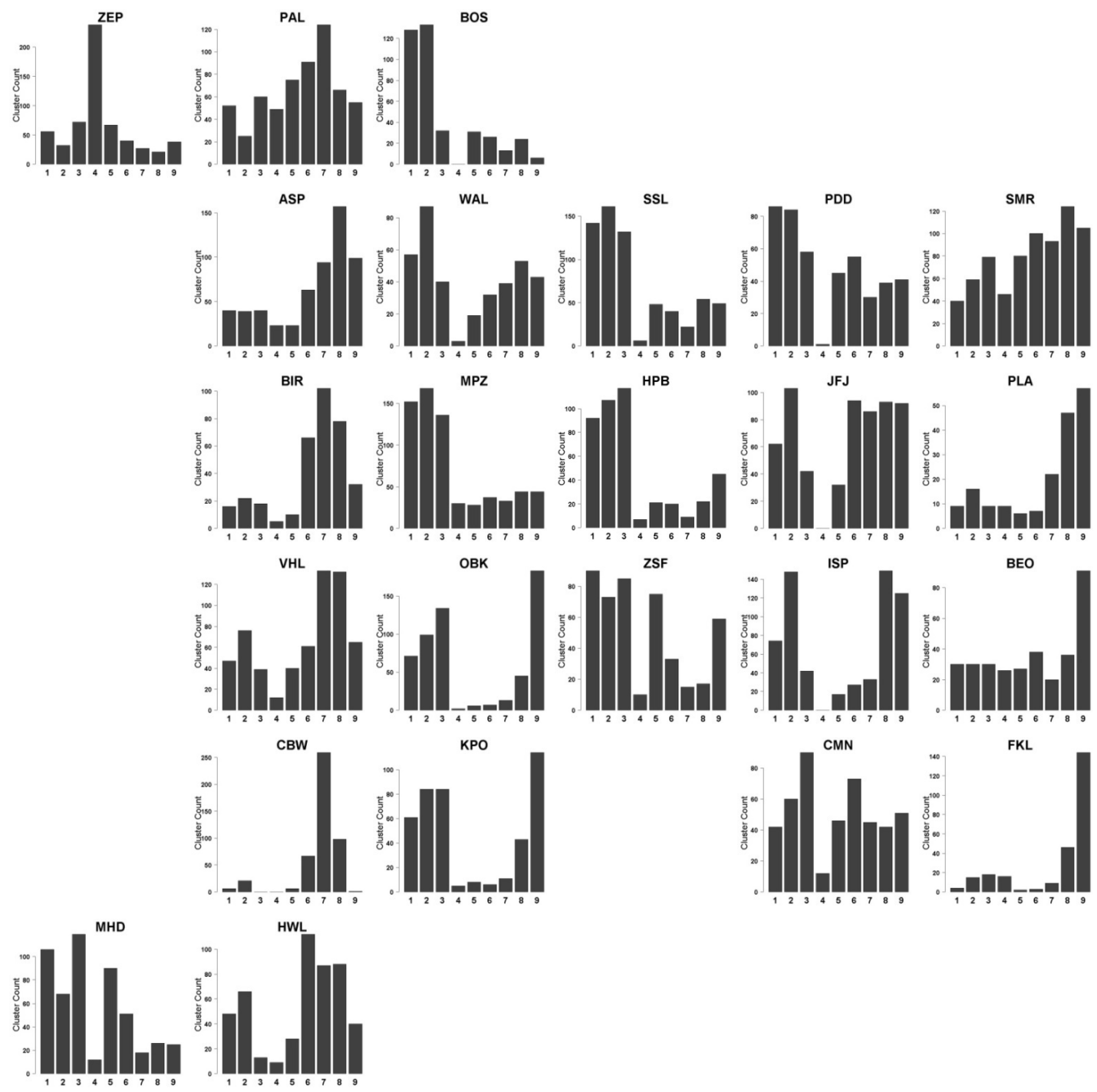

Fig. 3. Frequency of the clusters measured at each of the sites arranged in columns of similar patterns.

there are likely to be many source regions influencing a site, whereas the remaining narrower distributions are most frequently detected at the northern, western and eastern European sites. The nucleation modes tend to be most frequently observed at the higher latitude sites north of, and west of, the industrial heart of Europe.

Clusters that show a temporal pattern likely to be associated with nucleation are Clusters $1,2,3,5$ and 6 . These are characterised by an increase in particle numbers in the smallest size range (below $20 \mathrm{~nm}$ ) at around 15:00 UTC with a mode that increases in size through the following hours
(Fig. 4). Figure S6 shows that these clusters show very different seasonal patterns. Clusters 1, 3, 5 and 4 have a higher percentage of occurrence during the winter months, whereas Clusters 6, 7 and 8 tend to have a higher occurrence during the summer months. Clusters 2 and 9 do not show a clear seasonal trend. At ZEP, Cluster 4 is most prominent over the winter, detected between September and April whereas Cluster 5 is observed mainly in the summer between March and August. This is in approximate agreement with the seasonal averages reported by Asmi et al. (2011) and Ström et al. (2003) who attributed the accumulation mode 

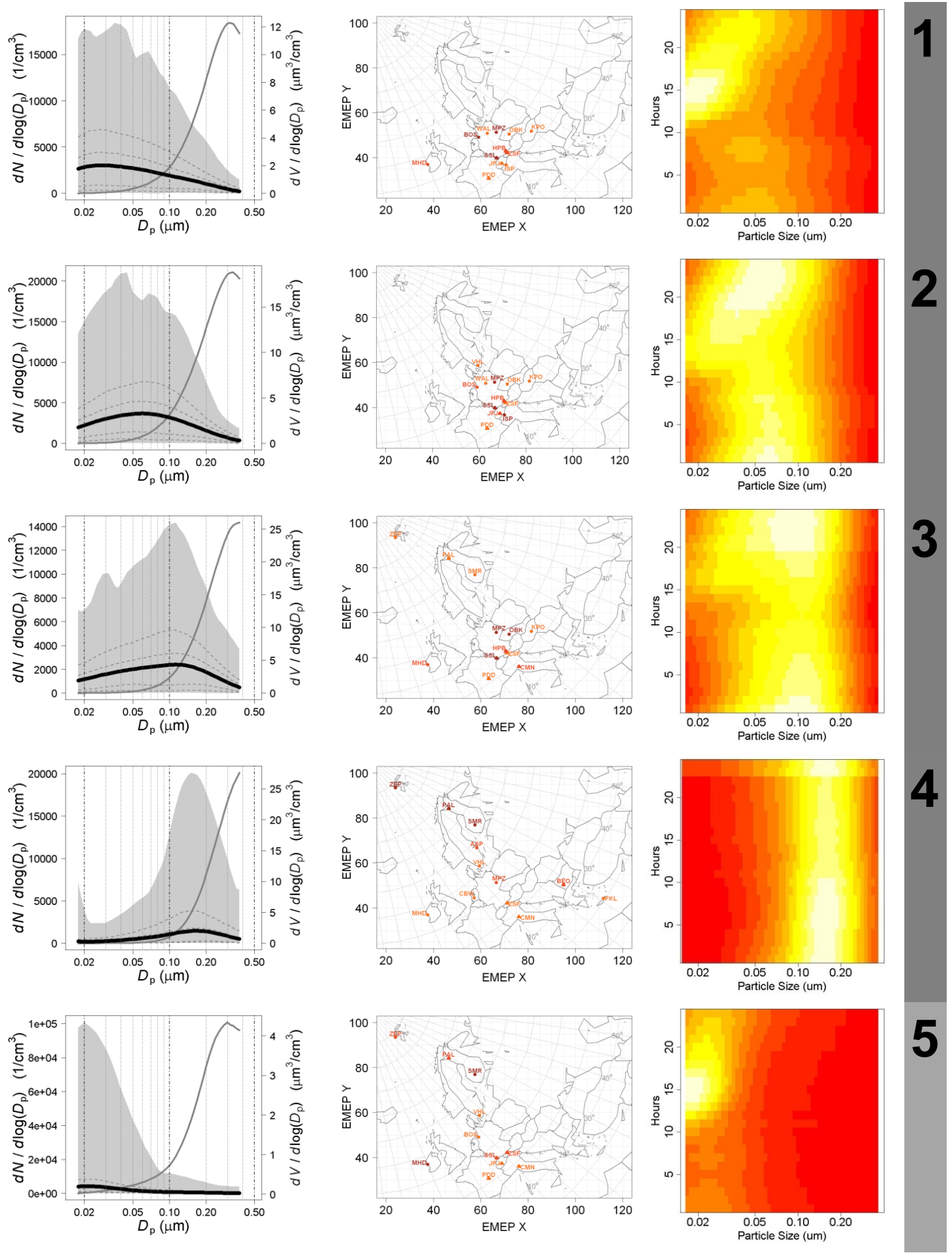

Fig. 4. Average clustered particle size distributions (Clusters 1-9 left hand panels) and the spatial distribution of each cluster (centre panels). The solid black line shows the average spectrum and the dashed lines show the 10th, 25th, 75th and 90th percentile spectrum. The maximum and minimum spectra are traced out by the extremities of the shaded areas. The middle panels show where each of the clusters are most likely to be detected. When counting the spectrum types within the whole data set, the sites which collected above the 90th, 75th and 50th percentile were marked with a progressively lighter orange colour (see Fig. S5 for the frequency distributions). Circles denote boundary layer sites and triangles denote sites of relatively high altitude. The right-hand panel shows the colour maps plotted using the average day of hourly spectra for each of the clusters. (The shade from red-yellow-white represents a linear scale of $d N / d \log \left(D_{\mathrm{p}}\right)$ between the minimum value of the 10th percentile spectrum and the maximum value of the 90th percentile spectrum shown for each cluster.) 

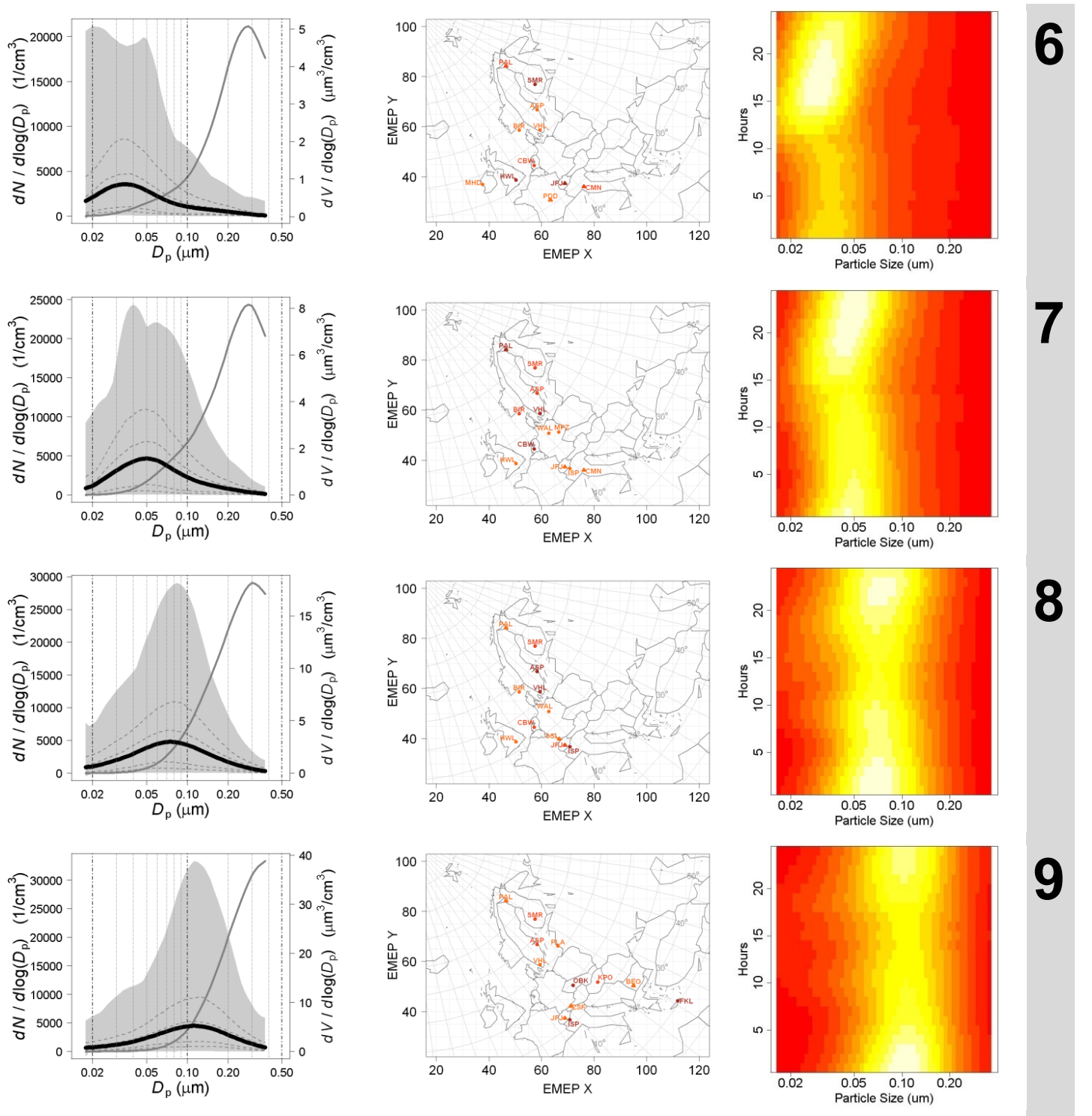

Fig. 4. Continued.

distributions to Arctic haze and the Aitken mode distributions to photochemical processes. At MHD, Cluster 5 peaks in April and September and is at a minimum during the winter months. Cluster 5, which shows a mode at one of the smallest diameters, may be consistent with nucleation processes. At some of the more remote sites (e.g. ZEP), Cluster 5 is observed mainly in the summer between March and August, but overall tends to show higher frequency in the cooler months. Since seasonal frequencies of nucleation vary across Europe, this may be the result of nucleation processes, but points to the fact that a given cluster may have more than one mechanism of genesis. Since Clusters 1, 2, 3 and 6 , which show the most obvious temporal growth process apparently driven by solar radiation followed by condensational growth at the colder temperatures in the evening, have a wide range of modal diameters, it seems probable that the common feature is that they are undergoing growth rather than necessarily being newly formed. Indeed, all of these distributions show marked breadth and include separate modes obscured by the overall umbrella curve. Clusters 1,2 and 3 all show a dominance of central European sites and also of mountain sites, presumably reflecting the relatively high concentration of potential substrates for gas-to-particle conversion processes or low condensation sink. Clusters 7 and 4 show predominant association with a single site. In the case of Cluster 7, most frequently measured at CBW, the size distribution is strongly suggestive of an aged vehicle exhaust aerosol in which the semi-volatile particles have evaporated leaving predominantly the larger non-volatile particles (Dall'Osto et al., 2011b). The presence of CBW in the 


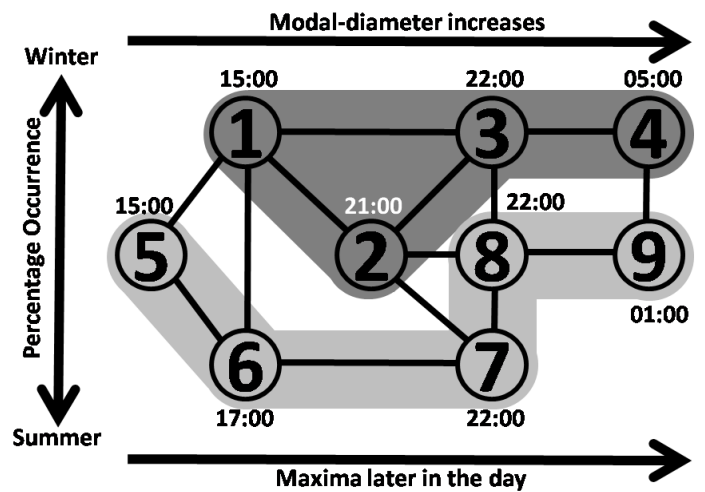

Fig. 5. Cluster proximity diagram. Each node in the diagram represents a cluster and each cluster is arranged according to its similarity to its neighbour. The modal diameter increases from left to right across the diagram and the two shaded regions indicate those clusters which are most frequently detected in central Europe (dark grey) and those which are not (lighter shades of grey). The times positioned next to each node indicate when the maximum particle number concentration of each cluster occurred.

heavily urbanised area of the Netherlands is consistent with such an explanation, although a number of Scandinavian sites in very much less polluted areas are also associated with this cluster. In the case of Cluster 4, one site (ZEP) accounts for around $50 \%$ of observations (Fig. S5) both in summer and winter. Cluster 4 shows a very strong association with the winter months (Fig. S6) and a very coarse modal diameter at around $150 \mathrm{~nm}$. This appears to be a strongly aged accumulation mode aerosol associated with the Arctic haze phenomenon. Clusters 4 and 9, both of which represent clusters with relatively coarse modes, show their highest abundance during nocturnal hours, presumably associated with low level nocturnal inversions and condensational growth.

\subsection{Categorisation of the nine clusters by cluster proximity diagram}

The results can also be generalised by the cluster proximity diagram in Fig. 5 for UTC. While $k$-means clustering matches together the most similar spectra into the nine clusters, the cluster proximity diagram positions these clusters according to the degree of similarity that each cluster has to each other. In other words, the closer the clusters are in the diagram, the more similar they are (Fig. 5). So for instance, Clusters 5 and 4 contain the most different spectra and hence there are at least two other clusters in between them on the diagram, whereas Clusters 2 and 8 are more similar. In essence, clusters next to each other on the diagram are similar to each other but not sufficiently similar to form a new cluster if merged. When arranging the clusters in this manner (represented by nine nodes in the diagram) trends can be extracted from the data. In this diagram, it can be seen that both the modal diameter of the clusters and the hour of the day at

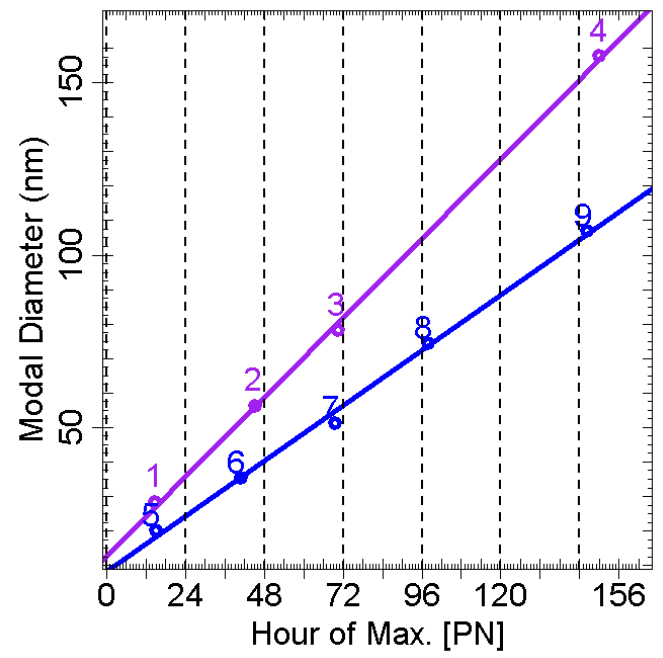

Fig. 6. Plot showing how the modal diameters MD of the average cluster spectra vary with the hour HR of their maximum particle number concentration [PN]. The purple (1, 2, 3 and 4) and blue (5, $6,7,8$ and 9) colours depict two aggregated trends observed in the data based on a south-to-north and west-to-east air mass movement. The rates of growth from cluster to cluster are: for the purple $(1,2$, 3 and 4) $0.9,0.9$ and $1.0 \mathrm{~nm} \mathrm{~h}^{-1}$; and for the blue $(5,6,7,8$ and 9) equal $0.59,0.55,0.82$ and $0.67 \mathrm{~nm} \mathrm{~h}^{-1}$ (fitted lines: $y=0.96 x+$ 12.8 and $y=0.67 x+8.11)$.

which the cluster reaches its maximum particle number concentration increases from left to right. These trends become evident when the modal diameter is plotted as a function of hour of maximum particle number concentration (Fig. 6).

The clusters furthest apart on the cluster proximity diagram, Clusters 5 and 4, have a geographic Arctic/Atlantic signature. However, their separation in the cluster proximity diagram is due to the fact that whilst Cluster 5 is the beginning of category representing the general movement of an air mass from west to east, Cluster 4 is the end product of another category representing the general movement of air mass from south to north. The cluster with the smallest modal diameter (Cluster 5, $\sim 22 \mathrm{~nm}$ ) occurs with greatest frequency at the coastal site of MHD and at the Arctic and Nordic sites of ZEP, PAL and SMR (see Tunved et al., 2013). In contrast, Cluster 4 is also most commonly observed at ZEP and then PAL and SMR but has much larger modal diameter of $0.16 \mu \mathrm{m}$.

Clusters 1, 2 and 3 are all linked together and occur most frequently in central Europe. The low-altitude MPZ and midaltitude SSL site are common to all of Clusters 1-3 as maximum occurrence sites. Clusters 1 and 2 exhibit similar characteristics in that both are nucleation mode clusters which enter the measurement size range during the afternoon as small particles due to photochemical processing of gases and then develop into larger particles in the evening and nighttime hours (see Fig. 4, colour map) and potentially sharing the same processes since Clusters 1 and 2 share the same 

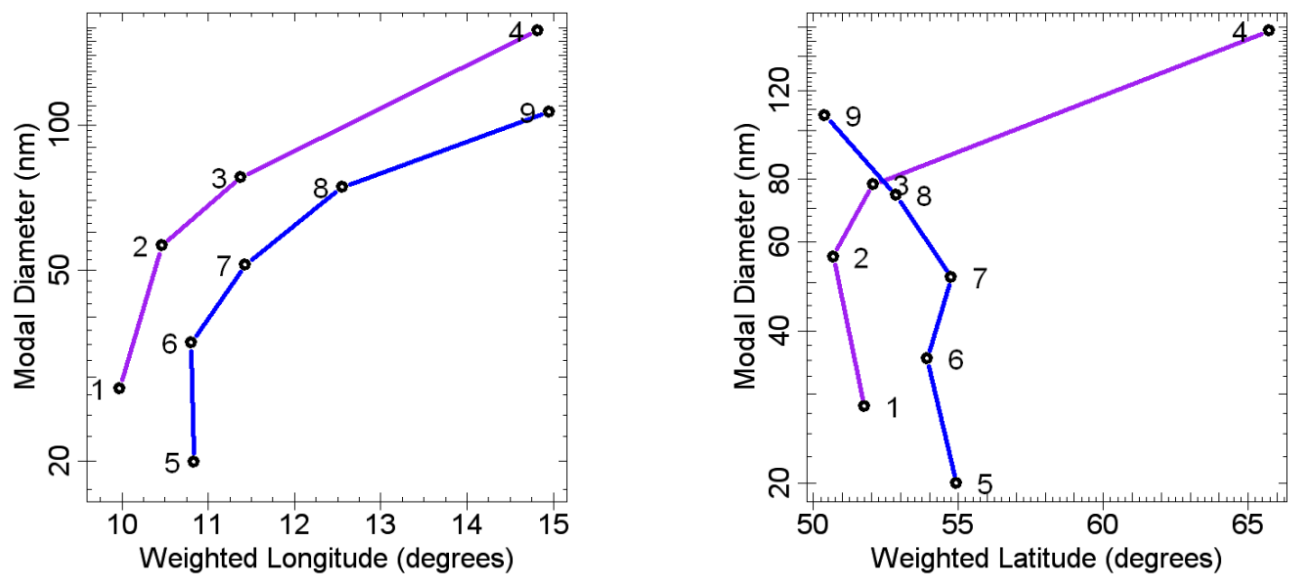

Fig. 7. Using the number distribution, the fitted modal diameter of each cluster (1-9) is plotted against the weighted longitude or latitude, calculated for each cluster, using $W L=\sum_{i}^{24} W_{i} \cdot X_{i} / \sum_{i}^{24} W_{i}$, where $X_{i}$ is the latitude/longitude of the sites where the cluster is detected and $W_{i}$ is the corresponding population of the cluster across the 24 sites. The purple $(1,2,3$ and 4$)$ and blue $(5,6,7,8$ and 9$)$ colours depict two aggregated trends observed in the data based on a South to North and West to East air mass movement.

sites of occurrence with the exception of MHD and VHL. Furthermore, the presence of Cluster 1 at MHD may indicate the influence of nucleation of particles in marine air (in the lower percentiles of the cluster) which then age as they move inland. The average spectrum of Cluster 3 is centred above $0.1 \mu \mathrm{m}$ and shares a similar 24-hour characteristic in its colour map as Clusters 1 and 2 suggesting that at some sites, this cluster occurs partly as a consequence of the presence of events and processes within Clusters 1 and 2.

At the furthest right hand of the cluster proximity diagram are Clusters 4 and 9 which include spectra from the later part of the aging process as the air moves on average from south to north or west to east. Cluster 9 is frequently observed in the two most easterly observatories BEO and FKL supporting the generalisation that as the air masses move to greater longitudes, the modal diameter of the size distribution increases as the air mass passes over the land (see Figs. 7 and S7 in the Supplement). Considering the site of Finokalia (FKL), Cluster 9 occurs throughout the year, being most prominent at this site during the months March, April and May. The colour map shows it to occur most during the night when the boundary layer is at its shallowest. This distribution typifies the aged and polluted aerosol distributions commonly observed in the eastern Mediterranean (Eleftheriadis et al., 2006; Hildebrandt et al., 2010; Kopanakis et al., 2013). Cluster 9 is also detected frequently during the summer at BEO and KPO. However, at ASP and SMR, the spectra in this cluster are more frequent during the winter-spring (JanuaryJuly). Although Cluster 4 is measured at BEO and FKL, it is most frequently observed over the Arctic and Nordic sites of SMR, PAL and ZEP and typifies the aged and polluted aerosol distributions commonly observed during the winter months in the Arctic which typify Arctic haze. It is important to note that part of the occurrence of Cluster 4 over Arc- tic and Nordic sites may also be originating from sea spray at high wind speed (Dall'Osto et al., 2011a).

Considering again the cluster proximity diagram and the position of the sites of frequent occurrence in Fig. 4 and Fig. S5 in the Supplement, it can be argued that the growth of nucleated particles is represented by the sequence of Clusters 5 to 8 (whose maxima occur sequentially at a later hour of the average day) which then feed the accumulation particles represented in Cluster 9. As the modal diameter increases from $22 \mathrm{~nm}$ in Cluster 5 through Clusters 6, 7 and $8(35 \mathrm{~nm}, 50 \mathrm{~nm}$, and $60 \mathrm{~nm})$ there is a tendency of the sites observing these clusters to move from the coastal and Arctic sites inland, reflecting the aging of aerosol as it passes across the land (see Sect. 4). Spectra from these clusters are also observed further inland at the mountain sites JFJ and ZSF. Also of interest is the observation that Cluster 5 peaks in frequency in the mid-afternoon and Cluster 9 occurs most during the night and morning. Clusters 5-9 and 4 are not frequently detected over the belt of industrial areas of Europe where the central European aerosol is generally observed. Referring to Figure S6, Clusters 3, 5 and 4, which are frequently detected at the Arctic, Nordic, Alpine and central European sites, are more frequently detected in the winter months between October and March. Clusters 6, 7 and 8 (pertaining to the Nordic and central European areas) show an opposite trend, peaking between April and October.

\subsection{Categorisation of the nine clusters by average modal diameters}

The average spectra of Clusters 1,2, and 3 can be described as broader versions of Clusters 5, 8 and 9 and are most frequently detected at one or more of the sites along the belt of boundary layer sites (including IPR) where central European 
aerosol is measured. The broad shape of the spectra of Clusters $1-3$ reflects different stages in the formation and growth of the central European particles (Fig. 2a) which represent the category south to north. Particle growth can be clearly seen separately in each of Cluster 1, 2 and 3, and by combining the colour maps into one, it is clear that they each represent a different stage of a complete cycle of particle growth (see Figure S8a). As later argued, these may develop in central Europe before being detected as Arctic haze at ZEP. In comparison, the spectra within Clusters 5-9 (representing the category west to east in Fig. 2b) individually show less evidence of growth within each of the average $24 \mathrm{~h}$ colour maps, and there is a greater spread of modal diameters across the clusters. However, when ordered according to modal diameter (from Cluster 5 to 9) progressive growth is again seen representing particle growth as the particles move from west to east across Europe albeit over a cycle much longer than for Clusters 1, 2, 3 and 4. Figure 6 exemplifies this further by showing how the modal diameters of the clusters grow with time. These use the times of maximum particle number concentration from the colour maps in Fig. 4 to discern time of day, with additions of $24 \mathrm{~h}$ to give the best fit to the curve. Growth rates average $0.93 \mathrm{~nm} \mathrm{~h}^{-1}$ and $0.66 \mathrm{~nm} \mathrm{~h}^{-1}$ for the two curves, but actually slow with growing particle diameter (see Fig. 6). Growth rates estimated from the west to east and south to north trajectories (see later) are of a similar magnitude. When repeating this analysis with nucleation and accumulation mode peaks derived from curve fitting to these clusters (Figs. S9 and S10 in the Supplement), it can be seen that this trend is peculiar to the nucleation mode. Growth rates of the nucleation mode peak 1 are rather slower than those for the mode of the full distribution seen in Fig. 6. The fitted growth rates are of a comparable order to those measured in situ (Kulmala et al., 2004).

Clusters 4 and 9 have the largest modal diameter amongst the sites and considering the trends shown in Fig. 6, tentative links can be made with particles emitted over central Europe or even sources nucleating particles detected mainly on the Atlantic coast respectively. When considering the sites where each of the nine clusters occur and the likelihood in terms of the percentage occurrence at each site, a general trend can be observed in that the larger the modal diameter of the cluster the greater the longitude of the site it was measured at. This trend is made clear by considering the modal diameters of each cluster plotted against the longitude and latitude weighted according to the population of the cluster at each of the 24 sites (Fig. 7). When carrying out this analysis, trends can be observed and separated into patterns which can be grouped according to whether the clusters are classified as "fast" or "slow" growing clusters, i.e. Clusters 1 to 2 to 3 to 4 and Clusters 5 to 6 to 7 to 8 to 9 respectively. Considering Clusters 5 to 9 , a clear increase in modal diameter can be seen with increased weighted longitude; this can be understood by the general movement of air masses across Europe, eastwards from the Atlantic. When consider- ing the same modal diameter plotted against weighted latitude, the increase in modal diameter can be observed with an overall decrease in weighted latitude, which can be understood by the bias of the strong detection of Cluster 9 at FKL. In the same way that the linear and curved trends passing through the modal diameters of Cluster 5 to 9 show the aging of aerosols passing from west to east, Cluster 4 can be linked to the central European Clusters 1, 2 and 3. When considering the modal diameters of Cluster 1 to 3 to 4 , an increase can be observed again with weighted longitude which can be understood by the movement of air masses from west to east. And again when considering the modal diameters $\varnothing$ of these same clusters with weighted latitude, significant growth $(\Delta \emptyset=30 \mathrm{~nm})$ is seen between Clusters 1 and 3 at roughly the same weighted latitude (central Europe) before Cluster 4 is detected $(\Delta \emptyset=40 \mathrm{~nm})$ along this sequence at a higher weighted latitude (corresponding to SMR, PAL and ZEP).

\section{Discussion}

While Asmi et al. (2011) sought to characterise sampling sites in terms of their particle size distributions, this paper seeks to understand better the relationships between those size distributions and the processes which influence them. Similar aims, but very different data analyses, were reported by Von Bismarck-Osten et al. (2013) in relation to measurements sites in and adjacent to four European cities. For central Europe, a principal components analysis of particle number size distributions was carried out on the basis of a multiple-site data set (Costabile et al., 2009). These authors found, for the east German region, statistically independent size distribution components and signature size distributions similar to this work: a nucleation mode $(\sim$ Cluster 1 from this work), an Aitken/aged nucleation mode ( $\sim$ Cluster 2 from this work), a first accumulation mode (corresponding to direct emissions and condensation), and a second accumulation mode resulting from cloud processing.

Considering these sequences of clusters plotted against weighted longitude/latitude, two clear trends can be seen between the modal diameter of the clusters and the weighted longitude/latitude. The cluster results show two different aging processes leading to Clusters 4 and 9 depending on whether the air masses are moving from south to north or west to east.

- Clusters 1, 2, 3 and 4 generalise the growth of particles formed in central Europe which first age over mid-latitudes before undergoing further aging as they are advected north (leading to Arctic haze) and/or east due to the prevailing wind patterns; and

- Clusters 5, 6, 7, 8 and 9 generalise a mechanism where particles age as they form at coastal sites and then pass over land from west to east. They will, of course, also 
be influenced by additional particles entering the air mass as it advects across Europe.

It is envisaged that by using a higher number of clusters in this analysis additional points along the purple plots (in Figs. 6, 7, and S7 in the Supplement) linking Clusters 3 and 4 , would result. But from these observations, a spatial generalisation can be made that at greater longitude the likelihood of detecting a cluster with a large modal diameter is increased. Similar trends are observed for the modal diameters measured in the equivalent volume distributions of the clusters (Fig. S7) except the trends for data plotted with respect to the weighted longitude are straighter. These trends are examined further through case studies of specific air mass trajectories (see Sect. 4.2).

\subsection{Influences on a measured particle size distribution}

Primary emissions frequently impact upon measured size distributions, especially when close to source. Most notable in this context are emissions from road traffic which have an immediate impact upon size distributions in the roadside environment, while advected particles will also impact considerably downwind of the source. For particles in the size range of less than $500 \mathrm{~nm}$ which are the focus of this paper, the relevant sources of primary particles are generally related to combustion and include point sources as well as road traffic line sources (Denier van der Gon et al., 2010). Fresh particles from road traffic exhaust typically show an overall mode at around $30 \mathrm{~nm}$ diameter comprising the sum of two modes; a mode at around $20 \mathrm{~nm}$ arising from nucleation of semi-volatile organic compounds and a mode at around $70 \mathrm{~nm}$ comprising particles with a graphitic core formed in the combustion chamber (Harrison et al., 2011).

Secondary nanoparticles arise from the nucleation of lowvolatility materials often requiring the formation of a sulfate nucleus which grows predominantly through condensation of oxidised organic compounds. Many studies have reported the observation of new particles formed through regional nucleation processes, starting at a few nanometres diameter and growing to several tens of nanometres over a period of hours (e.g. Alam et al., 2003; Kulmala et al., 2004). By plotting curves fitted through the modal diameter and maximum hours of occurrence of Clusters 1, 2, 3 and 4 and Clusters 5, $6,7,8$ and 9 , a growth process can be envisaged, as seen in Figs. 6 and S10 in the Supplement. Given the anthropogenic origin of Clusters 1, 2 and 3 in central Europe (with traffic being the dominant source), we would expect this trend to represent the growth of fresh emissions with a modal diameter of $20 \mathrm{~nm}$.

Both primary and secondary particles can grow and shrink in size within the atmosphere. Because they often comprise semi-volatile material, they are subject to condensational growth in areas of high vapour concentration but may shrink by evaporation if the particles move into a region of the atmosphere with low vapour concentrations such that the pres- sure of vapour in equilibrium with the particle's surface exceeds the environmental vapour pressure. The evaporation process has been clearly observed for particles generated from road traffic emissions (Dall'Osto et al., 2011b). In most circumstances, however, condensable vapours are continuously formed in the atmosphere through oxidation processes and the net process is one of condensational growth of particles.

In addition to condensational growth, particles can grow through coagulation. However, this requires relatively high number densities and at typical atmospheric concentrations coagulation is likely to be a rather slow process. It is most rapid between large and very small particles and consequently may impact on the number density of nanoparticles, whilst having little impact on the size, and no impact on the number of larger particles. While condensational growth leads to an increase in the mode of a size distribution without a change in particle number concentration, coagulation will cause a growth in the mode of the size distribution together with a simultaneous reduction in particle number concentration.

One of the main determinants of particle number concentration, especially in proximity of sources, is atmospheric dilution. Particles in a plume will reduce in number concentration as that plume dilutes downwind of a source or a city, with both lateral spread and vertical mixing to fill the surface boundary layer. Such processes are likely to dominate over deposition, although on longer timescales deposition processes can substantially influence the particle number concentration and size distribution. Both wet and dry deposition processes affect airborne particles and are most efficient for very small and very large particles. Particles in the accumulation mode of around 100-200 nm diameter are least susceptible to depositional processes and have a long atmospheric lifetime. Cloud processing can also substantially impact on the number and size distribution of particles, typically leading to particle growth through incorporation of vapour phase material into cloud water droplets which subsequently evaporate, and also by scavenging of multiple particles by single cloud water droplets.

\subsection{Air mass back-trajectory case studies}

The results from the cluster analysis are a static average picture of 2 years of the data set presented by Asmi et al. (2011). They give a good generalisation of how the particle number distributions are grouped together across the European map. The comparison of the clusters also gives an indication of the underlying processes at work as air masses pass across $\mathrm{Eu}-$ rope showing the aging of particles as they pass from west to east $(5,6,7,8,9)$ or from south to north (category 2 , Clusters $1,2,3,4)$.

To further test the evolution of particle size distribution across Europe, and to explore the processes behind their transformation, air masses passing over as many European 


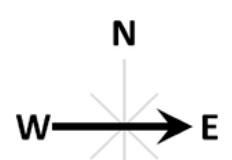

S

(a)


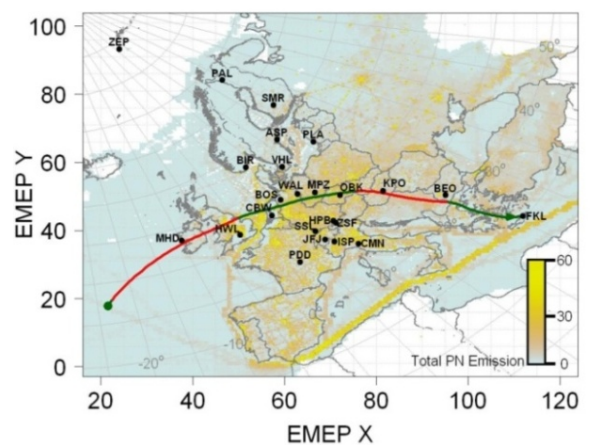

(b)

(c)



(d)

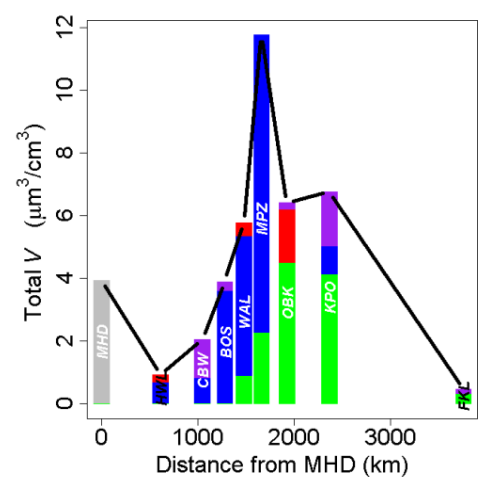

(e)

(f)

Fig. 8. Case study 1 (west to east). Temporal development of the particle size spectra plotted along the 5-day back-trajectory shown in plotted green/red from midnight to midnight on the particle number (PN) emission map shown in (b), starting southwest of MHD on 18 December 2008 and arriving at FKL on 24 December 2008 at 00:00. The stacked number and volume spectra (c, e) show the size distributions measured at the sites as the air mass passes. The modal diameter of the fitted distributions are indicated by circles and the progress plotted by the coloured lines which are coded to indicate the fraction of total number for each site plotted against distance in (d, f). The dotted lines in (c) and (e) are primarily to guide the eye, rather than being proposed as a firm causal connection.

sites as possible were considered along the main west-east and north-south geographical corridors formed by the EUSAAR sites. In order to do so, we present four case studies of four different air mass trajectories: case study 1 (MHD to FNK, west to east, Fig. 8), case study 2 (KPO to MHD, east to west, Fig. 9), case study 3 (JFJ-HPB to ZEP, south to north, Fig. 10) and case study 4 (PAL to CMN, north to south, Fig. 11). Each trajectory (calculated by BADC, the British Atmospheric Data Centre Trajectory Service) is plot- ted onto a particle number emission (PN) map (Denier van der Gon et al., 2010$)(\varnothing \leq 300 \mathrm{~nm}$ on a $7 \times 7 \mathrm{~km}$ grid $)$ in order to indicate the level of emission activity along the trajectory. The transit time between the monitoring sites was estimated and the particle size spectra at each monitoring site at the relevant trajectory time ( $1 \pm 1$ hour, total 3 hours) were extracted from the data set. Each of Figs. 8-11 has the same structure: (a) the wind direction studied; (b) the 5-day air mass back-trajectories; (c) the monitoring site-specific 


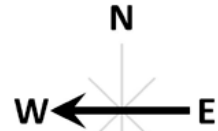

S

(a)
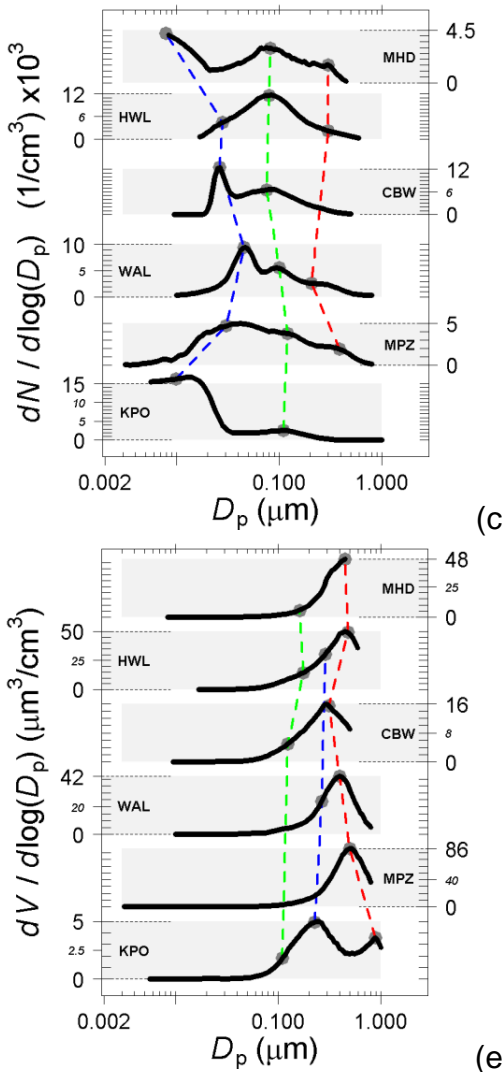

(c)

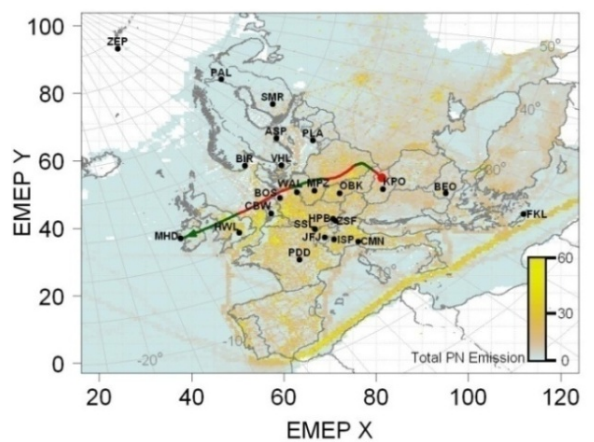

(b)

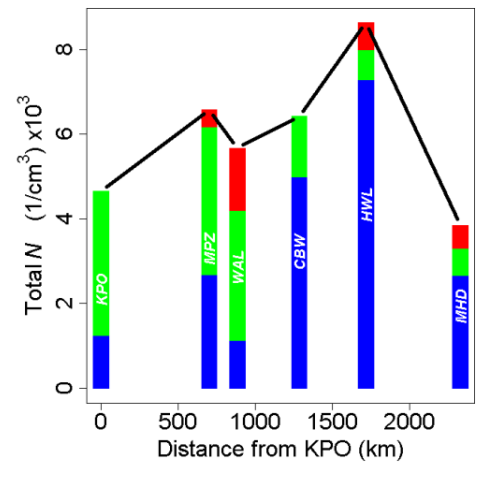

(d)

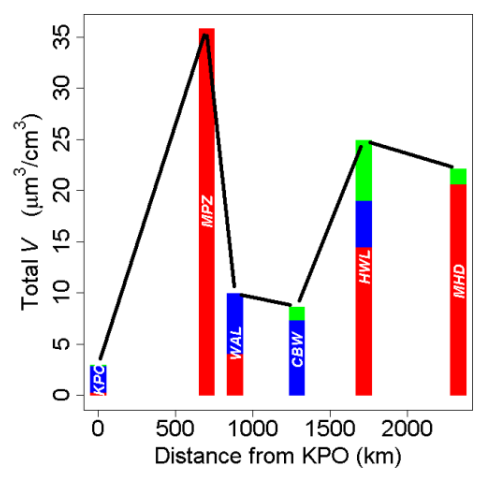

(f)

Fig. 9. Case study 2 (east to west). Temporal development of the particle size spectra plotted along the 5-day back-trajectory shown in plotted green/red from midnight to midnight on the particle number (PN) emission map shown in (b), starting at KPO on 11 April 2008 and arriving at MHD on 16 April 2009 at 18:00. Spectra collected from the nearest site to the air mass path are plotted in the left middle and (c, e). The peak fitted the modal diameters and area of each of these curves is shown on the middle and (d, f). The middle panels correspond to the metrics derived from the number spectra and the lower panels correspond to the metrics derived from the volume spectra. The dotted lines in (c) and (e) are primarily to guide the eye, rather than being proposed as a firm causal connection.

size-resolved particle number concentration averages; (d) the nucleation, Aitken and accumulation modes (in number concentration) of each monitoring site, obtained from the fitting of log normal modes to (c); (e) the monitoring site-specific size-resolved particle volume concentration averages; (f) the volume concentration of the accumulation, Aitken and accumulation modes of each monitoring site, obtained from the fitting $\log$ modes of (e). The modes were fitted to the number and volume distributions using the multi-peak fitting pack- age in Igor Pro 6.34A. Peaks were manually added and positioned until the optimum fit was achieved when the algorithm was run.

The resulting modal diameters are indicated by the grey dots on the spectrum stacks and areas under these fitted modes were plotted against distance from the site where the first recordable spectrum was measured. The dotted lines in Figs. 8-11c, e represent a tentative linkage indicative of possible evolution of particle modes along the trajectory. In the 


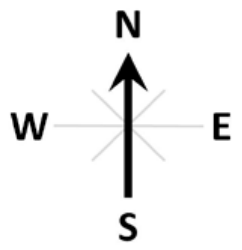

(a)


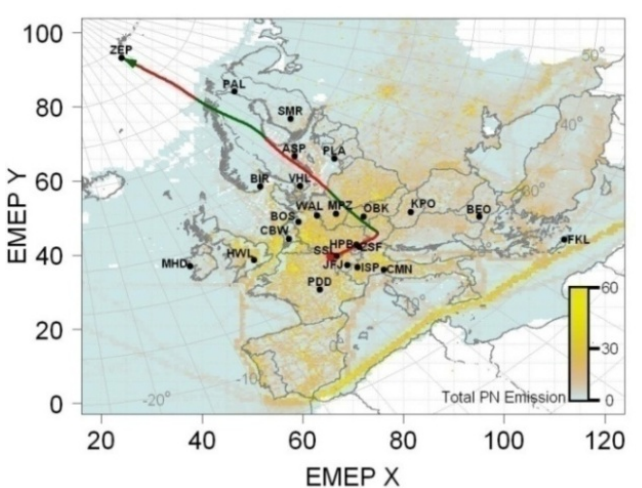

(b)

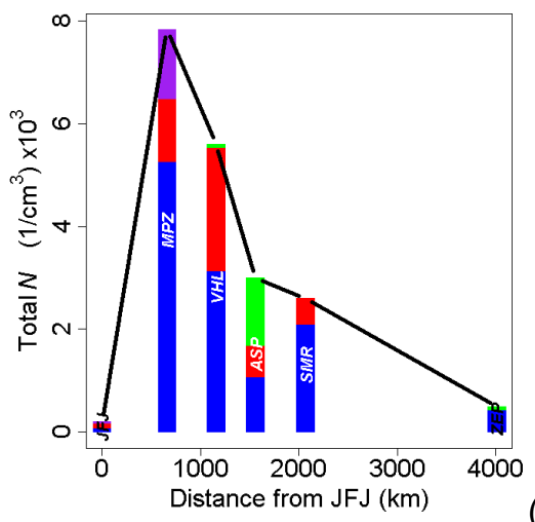

(d)

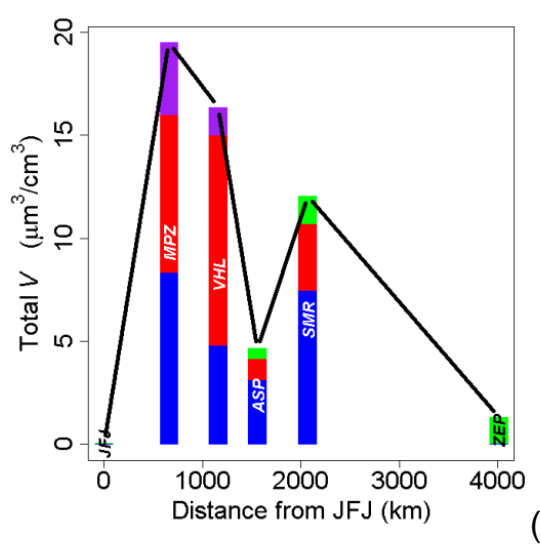

Fig. 10. Case study 3 (south to north). Temporal development of the particle size spectra plotted along the 5-day back-trajectory shown in plotted green/red from midnight to midnight on the particle number (PN) emission map shown in (b), starting at JFJ-HPB on 2 February 2008 and arriving at ZEP on the 7 February 2008 at 06:00. Spectra collected from the nearest site to the air mass path are plotted in (c, e). The peak fitted the modal diameters and area of each of these curves is shown in (d, f). The middle panels correspond to the metrics derived from the number spectra and the lower panels correspond to the metrics derived from the volume spectra. The dotted lines in (c) and (e) are primarily to guide the eye, rather than being proposed as a firm causal connection.

next four sections, details of each of the four case studies are presented.

\subsubsection{Case study 1: west-to-east trajectory}

Figure 8 shows an air mass trajectory started on 18 December 2008 off the West coast of the Republic of Ireland over the Atlantic Ocean in an area of frontal activity. A high 


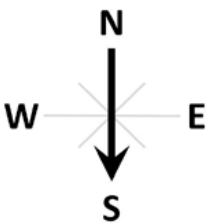

(a)

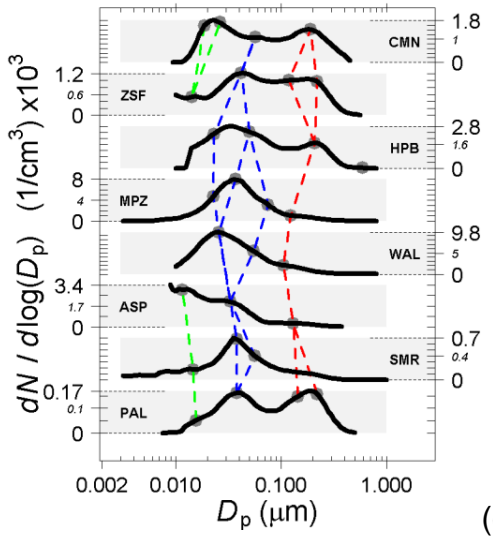

(c)

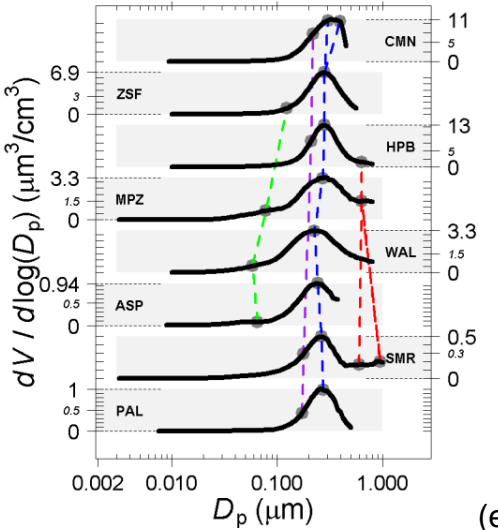

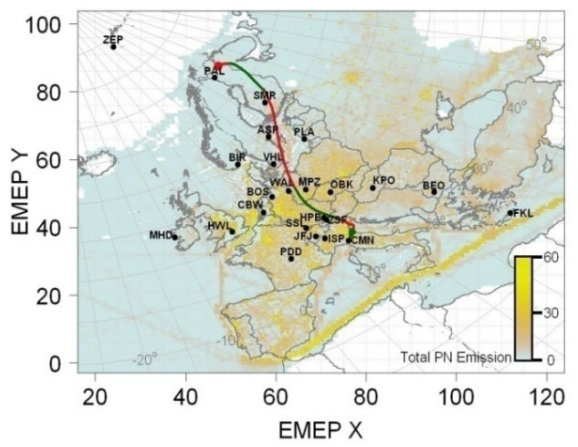

(b)

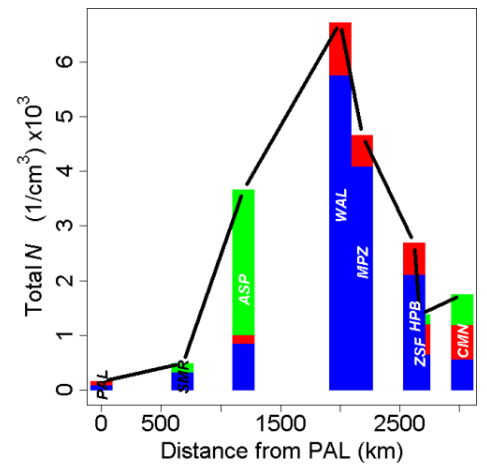

(d)

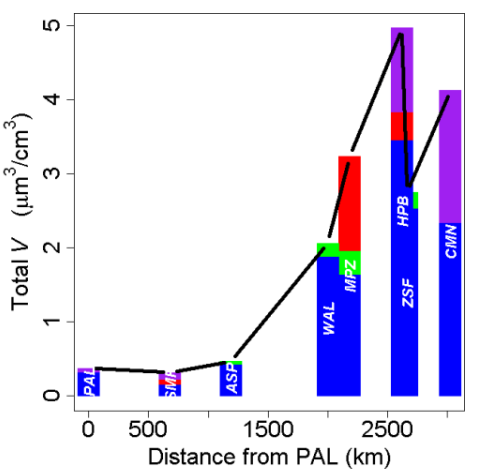

(f)

Fig. 11. Case study 4 (north to south). Temporal development of the particle size spectra plotted along the 5-day back-trajectory shown in plotted green/red from midnight to midnight on the particle number (PN) emission map shown in (b), starting at PAL on 12 October 2009 and arriving at CMN on 17 October 2009 at 18:00. Spectra collected from the nearest site to the air mass path are plotted in (c, e). The peak fitted the modal diameters and area of each of these curves is shown in (d, f). The middle panels correspond to the metrics derived from the number spectra and the lower panels correspond to the metrics derived from the volume spectra. The dotted lines in (c) and (e) are primarily to guide the eye, rather than being proposed as a firm causal connection.

percentage of cloud and rain accompanied the air mass as it passed over MHD and HWL (Figs. S11 and S12 in the Supplement). As the air mass passed from CBW to KPO between 21 and 22 December 2008, the synoptic charts for these two days indicate that the air mass trajectory passed between a region of high pressure, centred over France, and a region of low pressure positioned over the Nordic countries (Figs. S11 and S12 in the Supplement). Between these two regions of pressure two weather fronts stretched across the UK, along the path of the trajectory and into eastern Europe. Again, rain and cloud was present along the trajectory from $\mathrm{CBW}$ to OBK. The persistent rain and cloud is responsible for extensive aerosol deposition from the air mass.

From CBW to KPO the atmospheric pressure dropped from $1020 \mathrm{mb}$ to a minimum of $980 \mathrm{mb}$ at MPZ before rising again towards $1020 \mathrm{mb}$ at KPO. This low pressure was accompanied by between 80 and $100 \%$ cloud cover which then reduced to between zero and $40 \%$ after KPO. The high 
cloud cover is also reflected in the low downward short-wave radiation flux (DSWF) reaching a maximum of $50 \mathrm{~W} \mathrm{~m}^{-2}$ during the daytime, rising to 200 and $350 \mathrm{~W} \mathrm{~m}^{-2}$ after the air mass passes KPO. The planetary boundary layer height (PBLH) also kept to a low value of $\sim 500 \mathrm{~m}$ towards MPZ after which a diurnal cycle was re-established due to the clearer skies. After KPO, the PBLH reached a maximum of $1.7 \mathrm{~km}$. Rainfall was reported along the trajectory from CBW to MPZ (Figs. S11, S12 in the Supplement).

Overall, the meteorology along this trajectory was wet and cloudy up to the point when the air mass arrived at MPZ, when the weather pattern started to change to a situation where high pressure sat over the measurements sites on 23 and 24 December. Up until this point the downward solar flux was low due to the heavy cloud cover, which in turn led to a low boundary layer height. Regional nucleation would be very unfavoured under these conditions. In fact, precipitation scavenging explains the relatively low particle number concentrations accompanied by a strong accumulation mode due to the less efficient precipitation scavenging of this size range. Since the air mass originated over the Atlantic, a strong sea salt source (the coarse mode indicated in the volume spectrum, Fig. 8e) would be expected to contribute to the initial spectrum recorded at MHD. For this trajectory, hourly spectra were not available at HWL and FKL within the $\pm 1 \mathrm{~h}$ window used to select spectra, and in order to have some representation, $\mathrm{a} \pm 120 \mathrm{~h}$ window was used to generate spectra. Even so, within this compromise, the development of the particle size spectrum can be seen as a mode at $40 \mathrm{~nm}$ is observed at MHD and HWL which then grows to $50 \mathrm{~nm}$ at CBW corresponding to Cluster 7, having its highest frequency of detection. The hugely increased number concentration at CBW implies that direct emissions must be largely responsible. As noted in the previous section, this may be largely the result of road traffic emissions. The modal diameter then increased from $50 \mathrm{~nm}$ at CBW to $70 \mathrm{~nm}$ at MPZ (indeed moving from Cluster 5 type to Cluster 8 type, Figs. 4 and 5). There are two other modes which appeared along the trajectory with a lower and higher diameter, the larger of which contributed to the final spectrum causing Cluster 9 type spectra characteristic of FKL. In other words, this case study 1 is very well described by the cluster proximity diagram (Fig. 5), where the particle spectrum type moved from left to right across the bottom of the diagram from Cluster 5 to Cluster 9 showing the influence of aerosol aging and fresh emissions.

The air mass started with a total particle count just less than $1000 \mathrm{~cm}^{-3}$ at MHD and then grew significantly through $4000 \mathrm{~cm}^{-3}$ at HWL to a maximum of $12000 \mathrm{~cm}^{-3}$ at CBW. The mode common to MHD, HWL and CBW grew significantly after HWL, at which the main contribution was to a mode at $80 \mathrm{~nm}$. As the air mass passed over BOS, WAL and MPZ, the total number of particles $\mathrm{cm}^{-3}$ counted stayed under 4000 until MPZ after which it fell to below $1000 \mathrm{~cm}^{-3}$ (Fig. 8c, d). With regard to the volume, this steadily increased due to one mode at just below $0.2 \mu \mathrm{m}$ at HWL which developed right up until MPZ after which there was a staggered fall as the air mass approached FKL (Fig. 8e, f). It is also worth pointing out that between $\mathrm{CBW}$ and $\mathrm{KPO}$, where this size mode was observed, (i) there was almost $100 \%$ cloud cover, precipitation was present and the RH approached $100 \%$ favouring aqueous phase processing, and (ii) there were substantial anthropogenic emissions of particles and gases. After KPO, the RH steadily decreased together with the contribution to the total volume from these two condensation modes. Interestingly, a second mode was seen to appear at just below $0.2 \mu \mathrm{m}$ at WAL which then also started to grow as the air mass passed over MPZ, OBK and KPO before arriving at FKL. The growth of these two modes within overlapping time frames (both at a rate of $1.2 \mu \mathrm{m}^{3} \mathrm{~cm}^{-3} \mathrm{~h}^{-1}$ ) explains why there was a maximum volume observed at MPZ. After MPZ the total volume concentration fell, presumably due to deposition.

\subsubsection{Case study 2: east-to-west trajectory}

Whereas the west-to-east trajectory considered a case in the winter, the east-to-west trajectory case study was taken during the spring (11-16 April 2009; Fig. 9). At the start of the trajectory (11 April 2009), the air mass originated in a region of low pressure over eastern Europe with a slack pressure gradient and stagnated air which resulted in it taking 48 hours for the air mass to drift from KPO to MPZ (Figs. S13 and S14 in the Supplement). A large nucleation mode measured at KPO was washed out by a period of rain starting shortly after the air mass left KPO and headed to MPZ, after which the air mass experienced no rain, with an $\mathrm{RH}$ of $\sim 80 \%$ and temperature of $5-10^{\circ} \mathrm{C}$. Once past MPZ, the air pressure increased $(>1000 \mathrm{mb}$ ) until it passed over the UK where it dipped twice down to $980 \mathrm{mb}$ between CBW and HWL and HWL and MHD. The DSWF showed a typical diurnal pattern reaching a maximum of $600-700 \mathrm{~W} \mathrm{~m}^{-2}$ during the day which was modulated by the presence of cloud at around $40 \%$ over MPZ, WAL, CBW and as high as $80 \%$ over HWL. This sequence of washout followed by clearer skies promoted the nucleation and growth of particles seen in the number spectra. The baseline of PBLH rose from $\sim 100 \mathrm{~m}$ at $\mathrm{KPO}$ to $1000 \mathrm{~m}$ at MHD, peaking during the day at its highest value of $1.5 \mathrm{~km}$ at MPZ (Figs. S13 and S14 in the Supplement). As the air mass approached MHD (16 April 2009), the cloud cover reached $100 \%$ and was accompanied by rain as it coincided with a cold weather front between a low in the south and a high in the north of Great Britain.

The two particle spectra collected at KPO and MPZ were classified as of Cluster 1 type before developing into Cluster 2 type spectra at WAL, and finally ending as Cluster 3 type spectra at MHD. Whilst this structure begins and ends as category 1 clustering type, the intermediate monitoring sites at CBW and HWL presented a Cluster 8 type structure. In other words, this sequence of cluster classifications does not 
follow an intuitive trend (even across the cluster proximity diagram). Also, because of the relatively dry conditions compared to the previous west-to-east scenario, nucleation peaks were detected with the stagnating air mass which progressively decreased in number density when approaching MHD. MPZ was the first site free of rain, and showed a multi-modal distribution. There was a considerable loss in volume from MPZ to WAL and CBW associated with a reduction in the accumulation mode, but growth of a nucleation mode was seen. This however was lost at HWL but grew in again at MHD. Local sources including nucleation and deposition processes appear to be the dominant factor for this trajectory. In summary, from the east-to-west trajectory case study 2 (Fig. 9), it is clear that it is more difficult to develop a mechanistic interpretation of the development of the particle number and volume spectra than for the west-to-east trajectory case study 2 (Fig. 8). This may be due to the greater complexity in the initial aerosol composition over land compared to the relatively clean air originating over the Atlantic Ocean.

\subsubsection{Case study 3: south-to-north trajectory}

Case studies 1 and 2 considered air mass back-trajectories moving at relatively constant latitude across the European continent. In contrast, case studies 3 and 4 are based upon air mass back-trajectories moving at relatively constant longitude across the European continent. In case study 3, the air mass moved from land to sea, but this time arriving at the Arctic site of Zeppelin (ZEP) and starting from the relatively clean air sites of JFJ and HPB (typified by Cluster 7, see Fig. 10).

The synoptic maps for the beginning of February 2008 show a persistent weather system with low pressure over the UK and high pressure over eastern Europe causing the air mass considered in our trajectory to travel up from HPB to ZEP crossing a cold and cold/warm weather front as the air mass approached ZEP (Figs. S15 and S16 in the Supplement). Most noticeable in the meteorology was the presence of snow and rain as the trajectory passed between SMR and ZEP. This was reflected in the temperature profile as the value fell below $0^{\circ} \mathrm{C}$ between ASP and ZEP which otherwise rose to a maximum of around $5^{\circ} \mathrm{C}$. The cloud cover along the trajectory was high, dipping away from $100 \%$ and the DSWF reached a maximum of $\sim 300 \mathrm{~W} \mathrm{~m}^{-2}$ during the day at the start of the trajectory and progressively became weaker over the 5 days. The PBLH varied between $\sim 600 \mathrm{~m}$ before climbing to $1400 \mathrm{~m}$ half way between SMR and ZEP.

The final particle size spectrum at ZEP was typical of the characteristic average spectrum measured at this site, described by Cluster 4 , which has the largest modal diameter of between $100 \mathrm{~nm}$ and $150 \mathrm{~nm}$. For the scenario considered in Fig. 10, the first site was JFJ and was relatively clean, being located at top of the Jungfraujoch above the boundary layer pollution. The second site on the trajectory was at MPZ and both the total particle number and volume were much higher at this boundary layer site. The modal diameters of $30 \mathrm{~nm}$ and $100 \mathrm{~nm}$ probably represented traffic aerosol and secondary particles respectively. As the air mass travelled north towards ZEP, fewer particle sources were encountered (see Fig. 10) and the particle number decreased to values comparable with the initial number at JFJ. Steady growth of modal diameters occurred with the nucleation mode at MPZ apparently transitioning to an accumulation mode at ZEP.

When comparing this case study with the cluster classification (Fig. 5), the spectra followed from left to right across the cluster proximity diagram from a Cluster 1 spectrum at MPZ to a Cluster 2 spectrum at VHL, which then becomes successively a Cluster 3 and Cluster 4 spectrum at SMR and ZEP, respectively. In other words, the south-to-north trajectories were generalised by the upper left-to-right nodal positions in the cluster proximity diagram. In summary, case study 3 well represents the second category of our study (south to north, Clusters 1, 2, 3 and 4). We do not include JFJ in the latter description, as it clearly experienced a different (free troposphere) air mass to MPZ.

\subsubsection{North-to-south trajectory}

For the north-to-south trajectory case study, trajectories were selected which passed through the Nordic countries, across central Europe to CMN. The chosen trajectory arrived at CMN on 17 October 2009 (Fig. 11). The air mass encountered mainly cloudy conditions and the spectra appeared more representative of local sources due to the quicker removal times at lower particle sizes $(<50 \mathrm{~nm})$. Throughout the 5-day duration of the trajectory path (12-17 October 2009), the synoptic charts showed a high pressure centred over the southern UK with low pressure in eastern Europe. The trajectory began at the PAL monitoring site (12 October 2009), moved quickly over MPZ during the first 2 days and took a further 3 days to pass by HPB, ZSF before finally arriving at $\mathrm{CMN}$. The cloud cover remained high (90-100\%) along the trajectory, falling towards $0-20 \%$ between SMR and ASP (Figs. S17 and S18 in the Supplement). However, the diurnal patterns of the DSWF were distinct, reaching a maximum of $400 \mathrm{~W} \mathrm{~m}^{-2}$ in the daytime. There were patches of rain along the trajectory between ASP and WAL and between ZSF and CMN due to a weather front. As to be expected, the temperature increased from $-10^{\circ} \mathrm{C}$ at PAL to a daytime high of $20^{\circ} \mathrm{C}$ at $\mathrm{CMN}$ and the $\mathrm{RH}$ dropped from $100 \%$ to between 40 and $60 \%$ at CMN (Figs. S17 and S18 in the Supplement). It should be noted that the final three stations are all sited at high altitude, which will have influenced the data (HPB $988 \mathrm{~m}$; ZSF $2670 \mathrm{~m}$ and CMN $2165 \mathrm{~m}$ a.s.1.)

When classifying these, it is interesting that bimodal distributions are observed which are not clearly identified as belonging to any of our clusters until considering the lower percentile of the distributions - e.g. ZSF, HPB and CMN all belong to Cluster 2 identified by the lower percentile distributions (see Fig. S19). The remaining spectra are assigned 
as follows: PAL Cluster 3; SMR Cluster 6; and WAL and CMN Cluster 1. In this classification, there is no discernible trend across the cluster proximity diagram, although it can be seen that two modes are detected at PAL at $30 \mathrm{~nm}$ and $200 \mathrm{~nm}$ which are possibly due to a previous Arctic haze event. In other words, whilst case study 3 (south to north) well described the second aerosol clustering category, the current case study 4 (north to south) does not. Differences in the trend in number and volume concentrations along the trajectory are striking (Fig. 11). Both start low, but while particle volume (Fig. 11e) shows a broadly upward trend with distance (falling slightly at ZSF), particle number peaks (Fig. 11c) sharply at WAL and MPZ and then declines steadily. These appear to be large injections of fresh primary particles in the vicinity of WAL and MPZ which subsequently decrease with ageing, while these and gas-to-particle conversion lead to a steady increase in accumulation mode particles (Fig. 11e). By the time the air mass reaches CMN (17 October 2009, Fig. 11), a third mode at $20 \mathrm{~nm}$ is observed. The equivalent volume distribution shows a consistent and persistent mode at $200 \mathrm{~nm}$ which remains but grows in volume throughout the course of the trajectory.

\section{Conclusions}

Two years of harmonised-daily EUSAAR number size distribution data collected and averaged from 24 European field monitoring sites have been analysed using $k$-means cluster analysis. The results generalise the European near-surface aerosol particle size distributions and show to what extent neighbouring sites share common size distributions. These characteristics give insights into the aerosol processes at work and the likelihood of their occurrence. Rather than being restricted to specific areas, as would be expected considering the characteristic average shapes of particle spectra at the various sites (Asmi et al., 2011), the clusters all have a likelihood of being detected at a large proportion of the sites. In general, a central vs. outer Europe divide was observed when considering the median to upper quartiles of the frequency of detection at each site, and when merged into two groups, nucleation and growth of particles can be observed on two timescales. The clusters detected most frequently within the central European region - in and around Germany where the spatial density of emissions is anticipated to be high - had less seasonal dependence and much broader nucleation and accumulation modes, reflecting the increased likelihood of more diverse emission sources from anthropogenic emissions mixing into an air mass. At the higher number concentrations, these merge into a continuous curve with a single modal diameter whereas at lower concentrations, a bimodal distribution was present which accounted for the lower likelihood of these cluster types being detected at extreme locations at the Nordic, Alpine and Arctic sites. In particular, the diurnal trends in the spectra showed strong evidence of afternoon growth of nucleated particles within these central European clusters. In contrast, the remaining six outer-European clusters did not show as fast a development in the nucleation and growth of particles on a regular diurnal scale but instead collectively showed a modal diameter dependence on the longitude (from west to east) of the site at which they were most likely to be detected. Nucleationtype clusters $(<20 \mathrm{~nm})$ were most likely to be observed at the sites close to the Atlantic coast and as the modal diameter shifted from cluster to cluster, the most frequent site of detection moved across Europe to the distant sites in the Mediterranean and Arctic regions where the modal diameter was greater than $0.1 \mu \mathrm{m}$. This effect is most strikingly seen when the modal diameters of the clustered spectra are plotted against the longitude of the sites where they were detected, weighted by the population of each cluster at the sites. A similar effect could be seen for the central European clusters which when linked with weighted latitude suggested a south-to-north transport and development of aerosol released in central Europe (with a modal diameter of $\sim 45 \mathrm{~nm}$ ) leading to Arctic haze (modal diameter $\sim 150 \mathrm{~nm}$ ) over 3 days. There also may be contributions from aerosol arising from the Saharan region, e.g. at ZSF, where the most frequent and significant transport of aerosols originates from Africa.

When considering the case studies of west-to-east and south-to-north air masses (Figs. 8 and 10) we can infer a growth rate. For the west-to-east case study, the modal diameter of the particles passing from HWL to MPZ grows at a rate of $\sim 2.9 \mathrm{~nm} \mathrm{~h}^{-1}$. This is double the growth rate of the modal diameter of the particles in the air mass travelling north from MPZ to ZEP which is calculated to be $1.3 \mathrm{~nm} \mathrm{~h}^{-1}$. These values are within the range of the values reviewed by Kulmala et al. (2004) who reported particle growth rates between 1 and $20 \mathrm{~nm} \mathrm{~h}^{-1}$, with exceptions of some estimates in coastal areas giving growth rates as high as $200 \mathrm{~nm} \mathrm{~h}^{-1}$ and the smallest reported growth rates around $0.1 \mathrm{~nm} \mathrm{~h}^{-1}$ observed in clean polar areas. A more recent study (Vaananen et al., 2013) has also shown very slow growth rates in northern Scandinavia $\left(<1 \mathrm{~nm} \mathrm{~h}^{-1}\right)$.

In summary, when considering the particle size spectra observed at each of the sites over which trajectories pass along the north-south and west-east axes of the EUSAAR sites, evidence of particle growth is observed. Case studies, which consider the movement of the air masses along the north-to-south and east-to-west axes of the EUSAAR sites, show much greater complexity, largely due to a more aged aerosol being present at the trajectory starting point. The two clear trends based on west-to-east and south-to-north air mass movement can be distinguished as belonging to two particle growth mechanisms:

1. The west-to-east particle development can be best seen in the volume spectrum as two volume modes within overlapping time frames which are seen to start with a modal diameter just below $0.2 \mu \mathrm{m}$, and are observed 
to grow to $0.7 \mu \mathrm{m}$ and increase in volume at a rate of $1.2 \mu \mathrm{m}^{3} \mathrm{~cm}^{-3} \mathrm{~h}^{-1}$.

2. The south-to-north trajectory particle development is best seen in the number spectra originating at JFJ. This clean air mass is fed with anthropogenic emissions before arriving at MPZ where it has a strong number mode at $40 \mathrm{~nm}$. The total number of particles is highest at MPZ and then steadily decreases as the air mass tracks north, and on its journey, the mode at $40 \mathrm{~nm}$ grows in modal diameter to $\sim 150 \mathrm{~nm}$ (Arctic haze).

Although these four case studies illustrate the key processes affecting the aerosol as air masses advect across Europe, they present only snapshots of behaviour which is strongly influenced by the prevailing meteorology and hence local conditions at the time of sampling. They do, however, serve to illustrate that the general trends expressed in the cluster proximity diagram (Fig. 5) are observable in individual panEuropean trajectories, as well as representing longer-term process averages. This study strongly suggests that the evolution of ultrafine and fine particles is heavily dominated by condensation processes, further demonstrating the remarkable dynamics of particles in the atmosphere.

\section{Supplementary material related to this article is available online at http://www.atmos-chem-phys.net/14/ 4327/2014/acp-14-4327-2014-supplement.pdf.}

Acknowledgements. The National Centre for Atmospheric Science is funded by the UK Natural Environment Research Council. This work was also supported by the European Union EUCAARI (Contract Ref. 036833) and EUSAAR (Contract Ref. 026140) research projects. Thanks are also expressed to the British Atmospheric Data Centre, which is part of the NERC National Centre for Atmospheric Science (NCAS), for providing access to calculated trajectories using data from the European Centre for Medium-Range Weather Forecasts.

Acknowledgements for the funding of data collection and harmonisation appear in Asmi et al. (2011) and in the interests of brevity are not repeated here.

Edited by: A. Petzold

\section{References}

Alam, A., Shi, J. P., and Harrison, R. M.: Observations of new particle formation in urban air, J. Geophys. Res., 108, 4093-4107, 2003.

Asmi, A., Wiedensohler, A., Laj, P., Fjaeraa, A.-M., Sellegri, K., Birmili, W., Weingartner, E., Baltensperger, U., Zdimal, V., Zikova, N., Putaud, J.-P., Marinoni, A., Tunved, P., Hansson, H.C., Fiebig, M., Kivekäs, N., Lihavainen, H., Asmi, E., Ulevicius, V., Aalto, P. P., Swietlicki, E., Kristensson, A., Mihalopoulos, N., Kalivitis, N., Kalapov, I., Kiss, G., de Leeuw, G., Henzing,
B., Harrison, R. M., Beddows, D., O’Dowd, C., Jennings, S. G., Flentje, H., Weinhold, K., Meinhardt, F., Ries, L., and Kulmala, M.: Number size distributions and seasonality of submicron particles in Europe 2008-2009, Atmos. Chem. Phys., 11, 5505-5538, doi:10.5194/acp-11-5505-2011, 2011.

Beddows, D. C. S., Dall'Osto, M. and Harrison, R. M.: Cluster Analysis of Rural, Urban and Curbside Atmospheric Particle Size Data, Environ. Sci. Technol., 43, 4694-4700, 2009.

Birmili, W., Weinhold, K., Nordmann, S., Wiedensohler, A.,Spindler, G., Müller, K., Herrmann, H., Gnauk, T., Pitz, M.,Cyrys, J., Flentje, H., Nickel, C., Kulhbusch, T., Lschau, G.,Haase, D., Meinhardt, F., Schwerin, A., Ries, L. and Wirtz, K.: Atmospheric aerosol measurements in the German Ultrafine Aerosol Network (GUAN) - Part 1: Soot and particle number distributions, Gefahrst. Reinhalt. L., 69, 137-145, 2009.

Boulon, J., Sellegri, K., Venzac, H., Picard, D., Weingartner, E., Wehrle, G., Collaud Coen, M., Bütikofer, R., Flückiger, E., Baltensperger, U., and Laj, P.: New particle formation and ultrafine charged aerosol climatology at a high altitude site in the Alps (Jungfraujoch, $3580 \mathrm{~m}$ a.s.l., Switzerland), Atmos. Chem. Phys., 10, 9333-9349, doi:10.5194/acp-10-9333-2010, 2010.

Boulon, J., Sellegri, K., Hervo, M., Picard, D., Pichon, J.-M., Fréville, P., and Laj, P.: Investigation of nucleation events vertical extent: a long term study at two different altitude sites, Atmos. Chem. Phys., 11, 5625-5639, doi:10.5194/acp-11-56252011, 2011.

Central Intelligence Agency: The World Factbook 2009, Central Intelligence Agency, Washington DC, USA, Appendix D: crossreference list of country data, 2013.

Charron, A. and Harrison, R. M.: Primary particle formation from vehicle emissions during exhaust dilution in the roadside atmosphere, Atmos. Environ., 37, 4109-4119, 2003.

Charron, A., Birmili, W., and Harrison, R. M.: Factors influencing new particle formation at the rural site, Harwell, United Kingdom, J. Geophys. Res., 112, 4210, doi:10.1029/2007JD008425, 2007.

Costabile, F., Birmili, W., Klose, S., Tuch, T., Wehner, B., Wiedensohler, A., Franck, U., König, K., and Sonntag, A.: Spatiotemporal variability and principal components of the particle number size distribution in an urban atmosphere, Atmos. Chem. Phys., 9, 3163-3195, doi:10.5194/acp-9-3163-2009, 2009.

Dall'Osto, M., Monahan, C., Greaney R., Beddows, D. C. S., Harrison, R. M., Ceburnis, D. and O'Dowd, C. D.: A statistical analysis of North East Atlantic (submicron) aerosol size distributions, Atmos. Chem. Phys., 11, 12567-12578, doi:10.5194/acp11-12567-2011, 2011a

Dall'Osto, M., Thorpe, A., Beddows, D. C. S., Harrison, R. M., Barlow, J. F., Dunbar, T., Williams, P. I., and Coe, H.: Remarkable dynamics of nanoparticles in the urban atmosphere, Atmos. Chem. Phys., 11, 6623-663, doi:10.5194/acp-11-66232011, 2011b

Denier van der Gon, H., Visschedijk, A., Johansson, C., Ntziachristos, L., and Harrison, R. M.: Size-resolved pan-European anthropogenic particle number inventory, paper presented at International Aerosol conference (oral), 29/8-3/9 2010, Helsinki, 2010.

EEA CSI 004-Exceedance of air quality limit values in urban areas (version 2), available at: http://www.eea.europa.eu/ data-and-maps/indicators/\#c5=\&c7=all\&c0=10\&b_start=0 (last access: November 2012), 2009. 
Eleftheriadis, K., Colbeck, I., Housiadas, C., Lazaridis, M., Mihalopoulos, N., Mitsakou, C., Smolík, J., and Ždímal, V.: Size distribution, composition and origin of the submicron aerosol in the marine boundary layer during the eastern Mediterranean "SUB-AERO" experiment, Atmos. Environ., 40, 6245-6260, 2006.

Harrison, R. M, Beddows, D. C. S., and Dall'Osto, M.: PMF analysis of wide-range particle size spectra collected on a major highway, Environ. Sci. Technol., 5522-5528, 2011.

Harrison, R. M. and Jones, A. M.: Multisite study of particle number concentrations in urban air, Environ. Sci. Technol., 39, 60636070, 2005.

Hartigan, J. A. and Wong, M. A.: A $k$-means clustering algorithm., App. Statist., 28, 100-108, 1979.

Hildebrandt, L., Engelhart, G. J., Mohr, C., Kostenidou, E., Lanz, V. A., Bougiatioti, A., DeCarlo, P. F., Prevot, A. S. H., Baltensperger, U., Mihalopoulos, N., Donahue, N. M., and Pandis, S. N.: Aged organic aerosol in the Eastern Mediterranean: the Finokalia Aerosol Measurement Experiment - 2008, Atmos. Chem. Phys., 10, 4167-4186, doi:10.5194/acp-10-4167-2010, 2010.

Kopanakis, I., Chatoutsidou, S. E., Torseth, K., Glytsos, T., and Lazaridis, M.: Particle number size distribution in the eastern Mediterranean: Formation and growth rates of ultrafine airborne atmospheric particles, Atmos. Environ., 77, 790-802, 2013.

Kulmala, M., Vehkamäki, H., Petaäjä , T., Dal Maso, M., Lauri, A., Kerminen, V.-M., Birmili, W., and McMurry, P. H.: Formation and growth rates of ultrafine atmospheric particles: A review of observations, J. Aerosol Sci., 35, 143-176, 2004.

Philippin, S., Laj, P. and Putaud, J.-P., Wiedensohler, A., de Leeuw, G., Fjaeraa, A., Platt, U., Baltensperger, U., and Fiebig, M.: EUSAAR An Unprecedented Network of Aerosol Observation in Europe, Earozoru Kenkyu, 24, 78-83, 2009.

R Development Core Team. R: A language and environment for statistical computing. R Foundation for Statistical Computing, Vienna, Austria, ISBN 3-900051-07-0, http://www.R-project.org/, 2010.

Reddington, C. L., Carslaw, K. S., Spracklen, D. V., Frontoso, M. G., Collins, L., Merikanto, J., Minikin, A., Hamburger, T., Coe, H., Kulmala, M., Aalto, P., Flentje, H., Plass-Dülmer, C., Birmili, W., Wiedensohler, A., Wehner, B., Tuch, T., Sonntag, A., O’Dowd, C. D., Jennings, S. G., Dupuy, R., Baltensperger, U., Weingartner, E., Hansson, H.-C., Tunved, P., Laj, P., Sellegri, K., Boulon, J., Putaud, J.-P., Gruening, C., Swietlicki, E., Roldin, P., Henzing, J. S., Moerman, M., Mihalopoulos, N., Kouvarakis, G., Ždímal, V., Zíková, N., Marinoni, A., Bonasoni, P. and Duchi, R.: Primary versus secondary contributions to particle number concentrations in the European boundary layer, Atmos. Chem. Phys., 11, 12007-12036, doi:10.5194/acp-11-12007-2011, 2011.
Ström, J., Umegard, J., Torseth, K., Tunved, P., Hansson, H.-C., Holmen, K., Wismann, V., Herber, A. and Konig-Langlo, G.: One year of particle size distribution and aerosol chemical composition measurements at the Zeppelin Station, Svalbard, March 2000-March 2001, Phys. Chem. Earth, 28, 1181-1190, 2003.

Tunved, P., Ström, J., and Krejci, R.: Arctic aerosol life cycle: linking aerosol size distributions observed between 2000 and 2010 with air mass transport and precipitation at Zeppelin station, Ny-Ålesund, Svalbard, Atmos. Chem. Phys., 13, 3643-3660, doi:10.5194/acp-13-3643-2013, 2013.

Venzac, H., Sellegri, K., Laj, P., Villani, P., Bonasoni, P., Marinoni, A., Cristofanelli, P., Calzolari, F., Fuzzi, S., Decesari, S., Facchini, M.-C., Vuillermoz, E., and Verza, G. P.: High frequency new particle formation in the Himalayas, PNAS, Vol. 105, 15666-15671, 2008.

Väänänen, R., Kyrö, E.-M., Nieminen, T., Kivekäs, N., Junninen, H., Virkkula, A., Dal Maso, M., Lihavainen, H., Viisanen, Y., Svenningsson, B., Holst, T., Arneth, A., Aalto, P. P., Kulmala, M., and Kerminen, V.-M.: Analysis of particle size distribution changes between three measurement sites in northern Scandinavia, Atmos. Chem. Phys., 13, 11887-11903, doi:10.5194/acp13-11887-2013, 2013.

Von Bismarck-Osten, C., Birmili, B., Ketzel, M., Massling, A., Petaja, T., and Weber, S.: Characterization of parameters influencing the spatio-temporal variability of urban particle number size distributions in four European cites, Atmos. Environ., 77, 415-429, 2013.

Wiedensohler, A., Birmili, W., Nowak, A., Sonntag, A., Weinhold, K., Merkel, M., Wehner, B., Tuch, T., Pfeifer, S., Fiebig, M., Fjäraa, A. M., Asmi, E., Sellegri, K., Depuy, R., Venzac, H., Villani, P., Laj, P., Aalto, P., Ogren, J. A., Swietlicki, E., Williams, P., Roldin, P., Quincey, P., Hüglin, C., Fierz-Schmidhauser, R., Gysel, M., Weingartner, E., Riccobono, F., Santos, S., Grüning, C., Faloon, K., Beddows, D., Harrison, R., Monahan, C., Jennings, S. G., O’Dowd, C. D., Marinoni, A., Horn, H.-G., Keck, L., Jiang, J., Scheckman, J., McMurry, P. H., Deng, Z., Zhao, C. S., Moerman, M., Henzing, B., de Leeuw, G., Löschau, G., and Bastian, S.: Mobility particle size spectrometers: harmonization of technical standards and data structure to facilitate high quality long-term observations of atmospheric particle number size distributions, Atmos. Meas. Tech., 5, 657-685, doi:10.5194/amt5-657-2012, 2012.

Zhang, T., Ramakrishnan, R., and Livny, M.: BIRCH: A New Data Clustering Algorithm and Its Applications, Data Min. Knowl. Disc., 1, 141-182, 1997. 